\title{
Small and meso-scale properties of a substorm onset auroral arc
}

\author{
H. U. Frey, ${ }^{1}$ O. Amm, ${ }^{2}$ C. C. Chaston, ${ }^{1}$ S. Fu, ${ }^{3}$ G. Haerendel, ${ }^{4}$ L. Juusola, ${ }^{2,5}$ T. Karlsson, ${ }^{6}$ \\ B. Lanchester, ${ }^{7}$ R. Nakamura, ${ }^{8}$ N. Østgaard,${ }^{5}$ T. Sakanoi,${ }^{9}$ E. Séran, ${ }^{10}$ D. Whiter, ${ }^{6}$ \\ J. Weygand, ${ }^{11}$ K. Asamura, ${ }^{12}$ and M. Hirahara ${ }^{13}$
}

Received 6 April 2010; revised 22 June 2010; accepted 28 June 2010; published 7 October 2010.

[1] We present small and meso-scale properties of a substorm onset arc observed simultaneously by the Reimei and THEMIS satellites together with ground-based observations by the THEMIS GBO system. The optical observations revealed the slow equatorward motion of the growth-phase arc and the development of a much brighter onset arc poleward of it. Both arcs showed the typical particle signature of electrostatic acceleration in an inverted- $\mathrm{V}$ structure together with a strong Alfvén wave acceleration signature at the poleward edge of the onset arc. Two THEMIS spacecraft encountered earthward flow bursts around the times the expanding optical aurora reached their magnetic footprints in the ionosphere. The particle and field measurements allowed for the reconstruction of the field-aligned current system and the determination of plasma properties in the auroral source region. Auroral arc properties were extracted from the optical and particle measurements and were used to compare measured values to theoretical predictions of the electrodynamic model for the generation of auroral arcs. Good agreement could be reached for the meso-scale arc properties. A qualitative analysis of the internal structuring of the bright onset arc suggests the operation of the tearing instability which provides a 'ropelike' appearance due to advection of the current in the sheared flow across the arc. We also note that for the observed parameters ionospheric conductivity gradients due to electron precipitation will be unstable to the feedback instability in the ionospheric Alfvén resonator that can drive structuring in luminosity over the range of scales observed.

Citation: Frey, H. U., et al. (2010), Small and meso-scale properties of a substorm onset auroral arc, J. Geophys. Res., 115, A10209, doi:10.1029/2010JA015537.

\section{Introduction}

[2] Embedded within the diffuse aurora there is discrete aurora, mostly in the form of east-west aligned auroral arcs with up to a few kilometers of width [Maggs and Davis, 1968] and sometimes thousands kilometers of length. Auroral arcs can remain relatively stable for extended time periods, especially during the growth phase of a substorm when these arcs move slowly equatorward at just a few tens of meters per second. Around magnetic midnight discrete arcs can become very active with fast motions of individual structures along the arc with speeds of several kilometers per second and a (mostly) poleward motion of the whole arc with speeds of

\footnotetext{
${ }^{1}$ Space Sciences Laboratory, University of California, Berkeley, California, USA.

${ }^{2}$ Finnish Meteorological Institute, Arctic Research Unit, Helsinki, Finland.

${ }^{3}$ School of Earth and Space Sciences, Peking University, Beijing, China.

${ }^{4}$ Max-Planck-Institut fuer Extraterrestrische Physik, Garching, Germany.

${ }^{5}$ Department of Physics and Technology, University of Bergen, Bergen, Norway.

Copyright 2010 by the American Geophysical Union. 0148-0227/10/2010JA015537
}

several hundreds of meters per second [Wagner et al., 1983; Frey et al., 1996]. Their appearance can change with either motions of substructures along the arc or deformation of the arc into smaller structures of $0.1-100 \mathrm{~km}$ size. A single arc may show motions of structures into opposite directions on both sides of it [Haerendel et al., 1996].

[3] Auroral arc structures are primarily identified by their optical appearance and their size [Elphinstone et al., 1996]. The largest of these structures are spirals [Oguti, 1974; Davis and Hallinan, 1976] that can reach hundreds of kilometers in size. The smallest-size distortions of auroral arcs are filaments of $100 \mathrm{~m}$ width [Lanchester et al., 1997; Trondsen and

\footnotetext{
${ }^{6}$ Space and Plasma Physics, School of Electrical Engineering, KTH, Stockholm, Sweden.

${ }^{7}$ School of Physics and Astronomy, University of Southampton, Southampton, U.K.

${ }^{8}$ Space Research Institute, Austrian Academy of Sciences, Graz, Austria.

${ }^{9}$ Planetary Plasma and Atmospheric Research Center, Graduate School of Science, Tohoku University, Sendai, Japan.

${ }^{10}$ LATMOS, IPSL, St-Maur des Fosses, France.

${ }^{11}$ IGPP, University of California, Los Angeles, California, USA

${ }^{12}$ Institute of Space and Astronautical Science, Japan Aerospace Exploration Agency, Kanagawa, Japan.

${ }^{13}$ Department of Earth and Planetary Science, Graduate School of Science, University of Tokyo, Tokyo, Japan.
} 
Cogger, 2001] and curls (1-5 km) that can only be clearly seen in small-angle cameras pointed to local magnetic zenith [Hallinan and Davis, 1970; Vogt et al., 1999]. The whole spectrum of spatial scales is completed by folds [Hallinan and Davis, 1970] and other meso-scale auroral features of $100-500 \mathrm{~km}$ that are occasionally embedded into or detached from the auroral oval [Frey, 2007; Séran et al., 2009]. The physical processes behind some of the these features are reasonably well established like the fast development of a strong upward field-aligned current that causes the development of the magnetic shear instability for spirals [Hallinan, 1976] or the Kelvin-Helmholtz instability acting on a fieldaligned current sheet for curls [Hallinan and Davis, 1970]. The origin of others, like detached afternoon arcs is still the topic of debate [Elphinstone et al., 1996; Henderson et al., 1998; Frey, 2007]. It is for instance highly controversial how much either electrostatic or dynamic wave-particle interactions contribute to the appearance of aurora and the dynamics of arcs and smaller structures [Bryant, 2002]. Interhemispherical currents can probably also play a role in defining the intensity of auroral features, as was suggested in a recent study about non-conjugate aurora [Laundal and Østgaard, 2009]. The relationship between auroral forms on different spatial and temporal scales has not been fully established because multisatellite data [Boudouridis and Spence, 2007] and ideally also a connection to groundbased observations is required for such a multiscale investigation [Amm et al., 2005]. The Cluster and Double Star missions provided much new insight into such open issues but the extended ground-based network of all-sky cameras and magnetometers and the Time History of Events and Macroscale Interactions during Substorms (THEMIS) spacecraft have only started providing data to attack such investigations.

[4] Particle precipitation changes the local plasma density [e.g., Séran et al., 2007] due to ionization. That can be seen most clearly when an individual arc moves across the beam of an incoherent scatter radar and temporarily changes plasma density and temperature within the probed volume [Lanchester et al., 1997]. Depending on the energy of the precipitating particles the ionospheric Hall and Pedersen conductivities are modified on small and large scales. Additionally, the energy input by the precipitating particles and the Poynting flux generate ion outflow [Strangeway et al., 2005; Chaston et al., 2007].

[5] The motion of whole arcs is caused by the relative motion of the auroral acceleration region with respect to the surrounding plasma [Haerendel, 1999]. Motions of small auroral structures are primarily interpreted as a consequence of physical motions of plasma structures in the acceleration region [Davis, 1978] and the associated horizontal electric fields are shorted out by the parallel potential drops high above the ionosphere [Haerendel et al., 1996; Séran et al., 2009]. Localized horizontal electric fields can often be seen even at ionospheric altitudes close to filaments of auroral arcs [Lanchester et al., 1998]. Therefore, auroral arcs and smallscale auroral features are important manifestations of the coupling between the magnetosphere and ionosphere and offer a unique way of studying the energy and momentum transfer between the regions.
[6] Studying the appearance and dynamics of auroral features can provide insight into the details and overall effect of arcs on the global system. The ideal situation for such studies is a combination of small- and large-scale optical observations with spacecraft measurements of magnetospheric plasma properties. The satellite provides data for plasma properties by making in situ measurements along its orbit. Ground-based experiments such as all-sky cameras and magnetometers provide 2D or 3D distributions of ionospheric parameters by remote-sensing. On January 28, 2008 such an ideal situation occurred when the Reimei spacecraft crossed over the system of THEMIS Ground-Based Observatories. Reimei observed dynamic motions of small-scale structures along an auroral arc which was also seen by two all-sky cameras on the ground. Reimei measured ion and electron spectra at $640 \mathrm{~km}$ altitude while two of the THEMIS spacecraft in the magnetotail were magnetically connected to the region of observation. In this paper we analyze this event and compare measured auroral properties to theoretical predictions and derive properties of a substorm breakup arc with embedded small-scale auroral structures.

\section{Instrumentation and Methods}

\subsection{THEMIS GBO All-Sky Imagers and Ground Magnetometers}

[7] The THEMIS project includes an array of 21 GroundBased Observatories (GBO) with panchromatic all-sky cameras (ASI) and magnetometers [Mende et al., 2008]. The ASI run at $3 \mathrm{~s}$ cadence with one second integrations and the magnetometers run at $2 \mathrm{~Hz}$. The ASI fields of view (FoV) partially overlap and allow a quasi-global view of the aurora in North America. Here we concentrate on the ASI stations Inuvik (INUV, geographic latitude/longitude 68.4/226.2 ${ }^{\circ}$, geomagnetic $71.2 / 275.1^{\circ}$ ) and Fort Yukon (FYKN, geographic $66.5 / 214.8^{\circ}$, geomagnetic $67.2 / 266.1^{\circ}$ ).

\subsection{Reimei Satellite}

[8] Reimei is the first Japanese small scientific satellite launched on August 24, 2005 [Saito et al., 2005]. It has a sun-synchronous polar orbit in the $0050-1250$ local time meridian at an altitude of $\sim 640 \mathrm{~km}$ with an orbital period of $98 \mathrm{~min}$. Reimei carries a three-CCD monochromatic auroral camera (MAC) [Sakanoi et al., 2003; Obuchi et al., 2008] and top-hat-type electron and ion energy spectrum analyzers (ESA/ISA) [Asamura et al., 2003, 2009]. Using the three-axis stabilized satellite attitude control system, the FoV of MAC can be pointed toward the magnetic footprints of Reimei simultaneously satisfying the full pitch angle coverage of the particle sensors.

[9] The FoV for each MAC channel is made as small as $7.6 \times 7.6^{\circ}$ to observe the fine scale structure of aurora. The imaging area at $110 \mathrm{~km}$ altitude is about $\sim 70 \mathrm{~km}$ square with a spatial resolution of $\sim 1.1 \mathrm{~km}$. The exposure time is usually $60 \mathrm{~ms}$ with a cycle of $120 \mathrm{~ms}$, and is completely simultaneous across all three channels. Three wavelengths are selected to observe auroral emissions at $\mathrm{N}_{2}^{+} 1 \mathrm{NG}(427.8 \mathrm{~nm})$, O green line $(557.7 \mathrm{~nm})$, and $\mathrm{N}_{2} 1 \mathrm{PG}(670 \mathrm{~nm})$. The 427.8 and $670 \mathrm{~nm}$ emissions are prompt emissions responding primarily to higher energy electrons [Steele and McEwen, 1990]. They can therefore be used to estimate the energy flux of precipi- 
tating electrons. The $557.7 \mathrm{~nm}$ emission is the result of a forbidden transition but still one of the brightest in the auroral spectrum. ESA and ISA measure auroral electrons and ions, respectively, in the energy range from 10 to $12000 \mathrm{eV} / \mathrm{q}$ with 32 logarithmic energy steps and a FoV of $4 \times 300^{\circ}$. Since the temporal resolution is $1.25 \mathrm{~ms}$ for each energy step, the temporal resolution for obtaining the full energy range is $40 \mathrm{~ms}$ corresponding to $300 \mathrm{~m}$ mapped to $110 \mathrm{~km}$ altitude.

\subsection{THEMIS Spacecraft}

[10] The five identical satellites of the THEMIS mission [Angelopoulos, 2008] allow tracking the motion of plasma and waves from one point to another and for the first time resolve space-time ambiguities in key regions of the magnetosphere. The probes are equipped with comprehensive and identical particles and fields instruments. During this event TH-E and TH-D were located within one hour difference from the local time sector of the auroral observations and provided information on the magnetospheric context.

\subsection{Magnetometer Analysis}

[11] In order to obtain the ionospheric equivalent currents for this event, data of more than 70 magnetometer stations have been analyzed with the Spherical Elementary Current Systems (SECS) technique [Amm, 1997; Amm and Viljanen, 1999]. The SECS technique makes use of the fact that the ionospheric (and ground) equivalent currents are always divergence-free [e.g., Fukushima, 1976]. Therefore they can be expressed as a superposition of divergence-free current systems. The locations of the SECS poles are distributed over the region of interest, and each SECS pole may have different amplitude. The magnetic field of the SECS can be expressed analytically. This allows calculating the ionospheric equivalent current density by determining the amplitudes of the SECS poles such that the superposed ground magnetic effect of the SECSs optimally matches the measured disturbance magnetic field on the ground. The locations of the SECS poles can be chosen freely, in order to best accommodate the location and density of the available measurement points. For the combined magnetometer network used here, the spatial resolution of the resulting ionospheric equivalent currents is $300 \mathrm{~km}$. The vertical component of the curl of the ionospheric equivalent currents, which can directly be derived from the amplitudes of the SECS poles, is proportional to the fieldaligned current density (FAC) in the case that the conductance is uniform, or in case that conductance gradients point along the electric field direction [Amm et al., 2002].

\subsection{Optical Flow Analysis}

[12] The motion of small-scale structures in the auroral images was analyzed using the method of optical flow analysis as developed by Horn and Schunck [1981]. This method determines the displacement of brightness in two images by solving the basic equation for the rate of change of image brightness in an iterative scheme. The method has the advantage of yielding flow vectors for each element of a twodimensional image. Its limitation is that it assumes a smooth flow over the whole image, which is not always the case for aurora images where arcs change shape and may appear/ disappear. This limitation was not a serious concern in the present situation as the observed arcs remained stationary in latitude during the Reimei observations (1058:10
1058:40 UT) and only showed motions of substructures along the arcs.

\section{Observations and Analysis}

\subsection{All-Sky Imager Observations}

[13] Reimei crossed the INUV and FYKN FoVs between 1057 and 1100 UT. During the $20 \mathrm{~min}$ before the Reimei pass both sites observed the slow equatorward motion of a weak auroral arc which we will here call growth-phase arc as it later developed into the substorm breakup arc. Shortly before substorm breakup the growth-phase arc had moved $200 \mathrm{~km}$ equatorward of Inuvik (Figure 1). A new short ( $70 \mathrm{~km}$ long) arc (we further call it arc1 because it was poleward of the two arcs) appeared southwest of Inuvik and $60 \mathrm{~km}$ poleward of the growth phase arc (we further call it arc2 because it was equatorward of the two arcs) at 1057:09 UT and further "grew" eastward (not shown). The keograms in Figure 1 are useful to understand the auroral motions in the meridional direction but the azimuthal auroral dynamics cannot be identified from them. To examine the azimuthal auroral dynamics we plot mosaics from all-sky images and compare them with the Reimei image data. Figure 2 shows the auroral mosaic images of Fort Yukon, Inuvik and Fort Smith from 1057 UT to $1101 \mathrm{UT}$ at $1 \mathrm{~min}$ time steps. The Reimei image data are overlaid on the mosaic image at 1058 UT since Reimei is closest to Inuvik at this time.

[14] By 1057:27 UT the new arc1 had grown $250 \mathrm{~km}$ toward the east and become visible in the keogram data along the central meridian of the Inuvik all-sky camera (Figure 1 (bottom)). At 1057:39 UT arc1 extended over $550 \mathrm{~km}$ in length and "grew" further east (Figure 2, mosaic 1058 UT). Simultaneously it brightened, developed small substructures, but remained stationary in latitude. Only at 1058:41 UT did arc 1 move poleward, while the growth-phase arc 2 became the dominating arc of the substorm expansion (Figure 2).

\subsection{Reimei Observations}

[15] Reimei passed the Inuvik and Fort Yukon all-sky imager FoVs between 1057 and 1100 UT. Figure 3 shows successive images taken by Reimei/MAC from 1058:12.38 to 1058:38.44 UT. During this period, Reimei was located over Inuvik (INUV), and observed the intense poleward arc1 extending east-westward with a typical width of $\sim 25 \mathrm{~km}$ from $~ 1058: 13$ UT to $\sim 1058: 26$ UT (Figure 3 (top)), followed by the equatorward multiple folded aurora (arc2) from $\sim 1058: 23$ to $\sim 1058: 37$ UT (Figure 3 (bottom)) (see Movie 1). ${ }^{1}$

[16] The advantage of Reimei is the capability of simultaneous image-particle measurements. However, for this event, there is about $10 \mathrm{~s}$ time difference between image and particle measurements as shown by the offset between the optical arc and the spacecraft magnetic footprint in Figure 3. When Reimei passed over the arc its magnetic foot print already "ran ahead" and measured the precipitating electrons before the arc came into view of the camera. The energy-time spectrograms for electrons and ions measured by Reimei/ESA and ISA are shown in Figure 4. From the precipitating electron data it is found that the intense poleward arc1 corresponds to high-energy monoenergetic inverted- $\mathrm{V}$ electrons with a peak

\footnotetext{
${ }^{1}$ Animations are available in the HTML.
} 


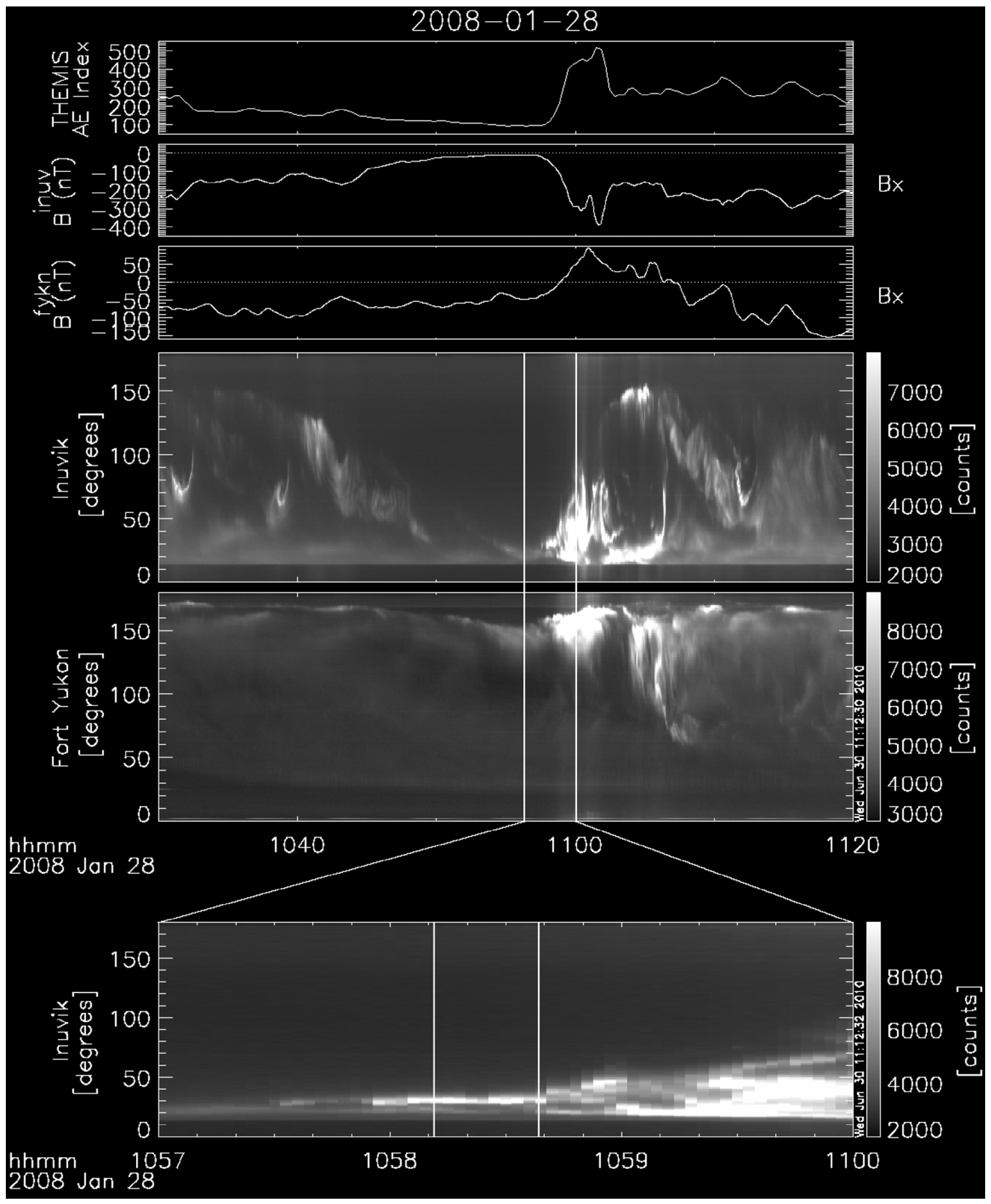

Figure 1. THEMIS pseudo-AE index, ground magnetic disturbance $x$-components and auroral keograms of the two sites Inuvik and Fort Yukon and (bottom) a blow-up of Inuvik showing the slow equatorward motion of the pre-existing auroral arc (1030-1055 UT) and substorm onset with brightening at 1057:30 UT followed by poleward expansion after 1058:40. The y-axis of the keograms shows elevation angle with $0^{\circ}$ at the southern horizon, $90^{\circ}$ in zenith, and $180^{\circ}$ at the northern horizon. The gray scale is given in raw instrument counts. The bottom panel marks the time interval 1058:10-35 when the Reimei optical and particle measurements were performed. 
1057 UT
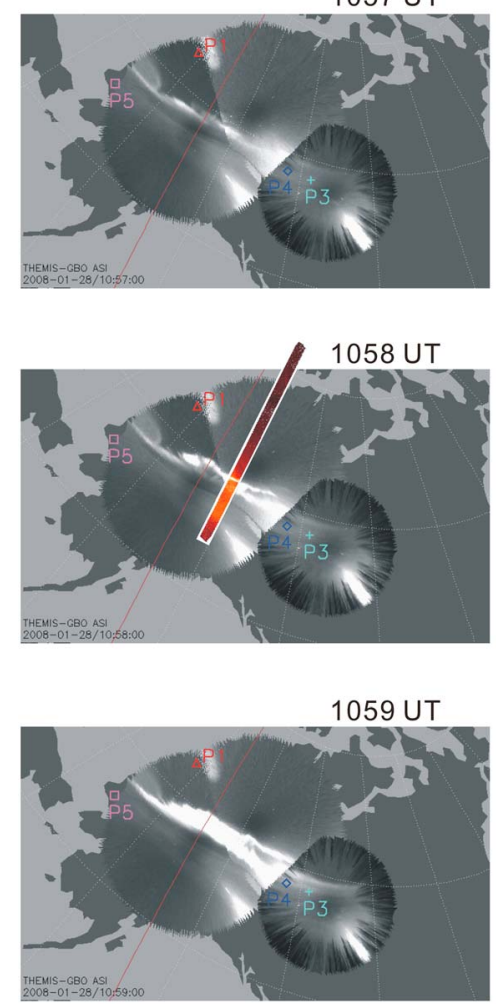

1100 UT

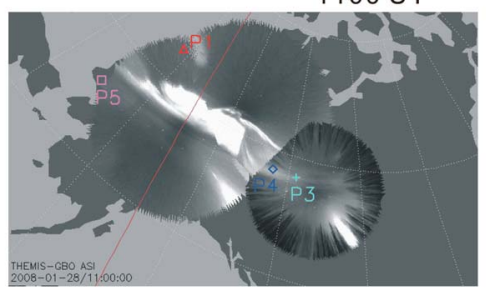

1101 UT

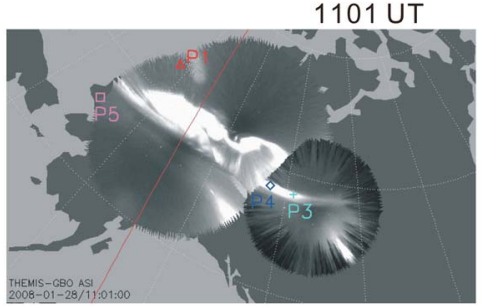

1058 UT expanded image



Figure 2. Mosaic images obtained from THEMIS GBO all-sky images at Fort Yukon, Inuvik, and Forth Smith at 1 minute intervals from 1057 UT to 1101 UT on January 28, 2008. Reimei image data are overlapped on the mosaic plot at $1058 \mathrm{UT}$, and the region of arcs 1 and 2 is expanded in the bottom right. The magnetic footprints of four THEMIS spacecraft are given. Magnetic midnight is marked by the red line.

energy of more than the energy range of ESA (12 keV/e) as measured from 1058:13 UT to 1058:17 UT.

[17] The precipitating electrons show the typical signature of an inverted-V with a significant supra-thermal electron burst in the most poleward region measured from 1058:09 UT to:13 UT (first and third panel Figure 4), suggesting the existence of Alfvénic acceleration [Chaston et al., 1999]. Since the maximum energy of supra-thermal electrons is only a few $\mathrm{keV}$, these just produced a weak $E$ region auroral emission in the poleward part of arc1. The generation process may be interpreted with the auroral leading edge model that explains the interaction between a poleward moving inverted-V potential drop and the topside ionospheric plasma [Haerendel, 1999, 2007]. Similar Alfvénic accelerated electrons have been reported previously at the leading edge of a substorm aurora [Mende et al., 2003a, 2003b]. However, these supra-thermal electrons are stronger compared to typical supra-thermal electrons that are normally measured during other times. Therefore, these supra-thermal electrons, namely the Alfvénic acceleration process, may be related to magnetospheric phenomena in association with the substorm onset and auroral break up. Further, unusual transversely accelerated ions occurred from 1058:07 to 1058:21 UT (fifth panel of Figure 4).

[18] The total inverted-V was measured by Reimei between 1058:09 and 1058:19 UT ( 75 km at $640 \mathrm{~km}$ alti- tude) and corresponds to a width of $\sim 65 \mathrm{~km}$ at $110 \mathrm{~km}$ altitude. It was thus wider than the optical arc width seen from images $(\sim 25 \mathrm{~km}$, Figure 3$)$. This suggests that the bright aurora was generated only by the large energy flux of the higher energy electrons, and the total energy flux input into the ionosphere covered a wider region than the optical auroral arc. The folded aurora (arc2) corresponds to the multiple inverted-Vs seen from 1058:21 UT to 1058:29 UT. Though these multiple inverted-Vs appeared as many isolated structures, it is likely from the arc 2 images that this was actually the cross section of a single folded inverted-V structure.

\subsection{THEMIS Spacecraft Observations}

[19] While the foot points of TH-D (P3) and TH-E (P4) as determined by the Tsyganenko T96 magnetic field model with corresponding solar wind parameters were located more than $1 \mathrm{~h}$ east of the local time of the Reimei crossing as well as the location of the auroral onset (Figure 2), they still corresponded to a region where activities of the auroral arcs reached in the course of their expansion. The foot point of TH-D was located eastward and equatorward of the TH-E foot point. Both spacecraft were located in the southern hemisphere and the magnetic field mapping across the neutral sheet may introduce uncertainties. However, we are mostly interested in their relative location and the qualitative agreement with observations in the ionosphere provides confi- 

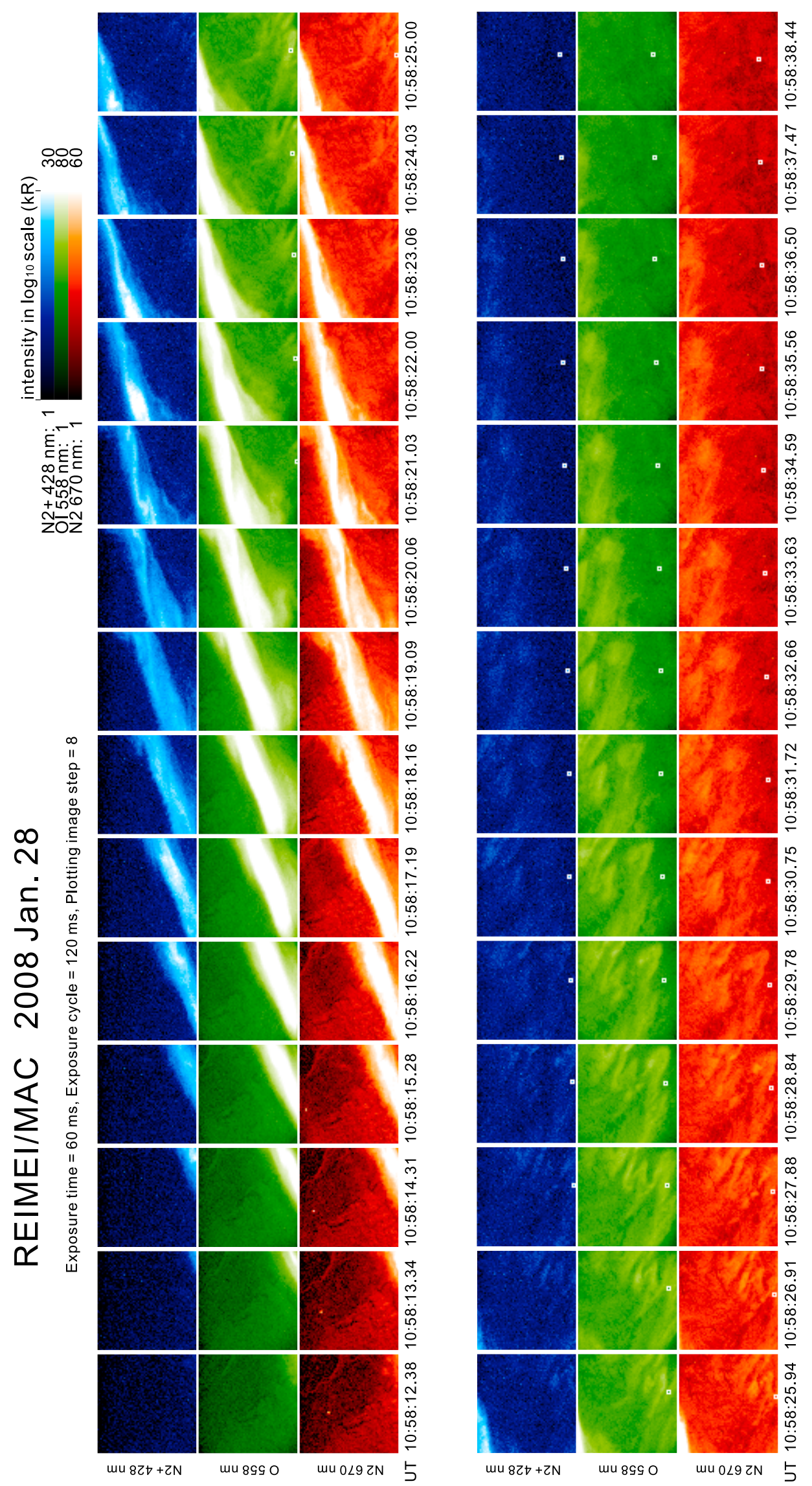

오를

哂恕

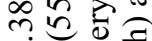

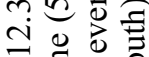

$\ddot{\infty} \equiv$ 웅

ำ 등

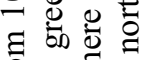

可丁

บ ิิ

\क⿱

ป ษ

○

$\simeq Z$ 舟

근 흉

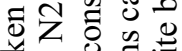

壱范

ข

(2)



舟

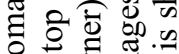

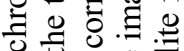

풍

을 至 的

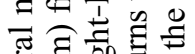

응 일

충으을

¿ $2 \frac{0}{0}$

की

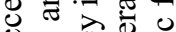

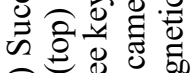

छ

芒焉过

이일

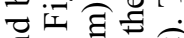

者

능 우웡

包包苋

м $\forall$ 卞

$\dot{\sim} \dot{\sim}=\underline{2}$

ڤ

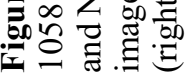

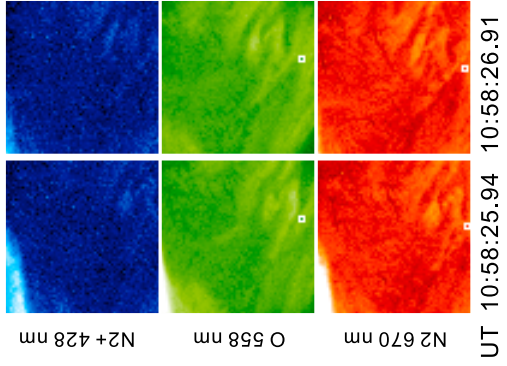






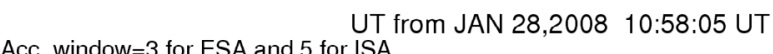

Mon Nov 23 03:18:46 2009

Figure 4. Energy-time spectrograms for electrons and ions measured by Reimei/ESA and ISA from 1058:05 UT to 1058:35 UT on January 28, 2008. The top three panels show field parallel, perpendicular and anti-parallel electrons, the bottom three panels show the same for ions.

dence that the mapping is not completely wrong. Around the time when Reimei crossed the arcs, the foot points of TH-E and TH-D were located at the eastern extension of the equatorward arc2. Later when the poleward arc1 expanded eastward (Figure 2 at 1059, 1100, 1101 UT) it reached also the local time of the TH-E and TH-D foot points associated with an equatorward expanding N-S slanted arc structure.

[20] TH-D (located at $-9.85,-4.51,-3.05 \mathrm{Re}$ in GSM coordinates) and TH-E (located at $-10.50,-3.79,-3.40 \mathrm{Re}$ ), which were located in the plasma sheet boundary layer, detected clear disturbances around the times when these auroral activations reached their foot prints, as shown in Figure 5. Fast earthward flow, accompanied by enhancements in $B_{z}$ (dipolarization), was seen by both spacecraft, although the most significant changes were the decrease in $\mathrm{B}_{\mathrm{x}}$ and plasma beta. The earthward flow started around 1058:10 UT faster and with longer duration at TH-E than at TH-D. Both spacecraft first observed a decrease in magnetic field magnitude and then the dipolarization $\left(B_{z}\right.$ increase) from
1058:30 UT at TH-E and from 1058:55 UT at TH-D, as indicated by the vertical lines in Figure 5.

[21] Considering the spatial and temporal relationships between the magnetospheric disturbance and the aurora we can interpret that the flow event was related to arc2. We examined the magnetic field and flow disturbances during the crossing to identify the possible structure of the magnetic field and flow shear and thereby to infer the possible FAC direction and to check whether it was consistent with the disturbances observed in the ionosphere. Figure 6 illustrates the flow disturbances perpendicular to the magnetic field in the $\mathrm{Y}-\mathrm{Z}$ plane during the crossing. Flow vectors show values relative to the average flow during the interval of the disturbance. The change in the flow pattern and possible direction of the FAC are illustrated at the bottom of the figure. The general sense of the flow disturbances was similar between TH-E and TH-D, indicating that there was the same shear flow pattern existing at $\sim 1 \mathrm{RE}$ scale in the azimuthal direction (distance between TH-E and TH-D), and suggesting a 




Figure 5. Magnetic field and plasma flow observations from TH-E and TH-D between 1055 and 1105 UT. For each spacecraft the ion energy spectra, the magnitude and the three components of magnetic field, ion flow perpendicular to the magnetic field, and ion flow in GSM coordinates are plotted from top to bottom followed by a panel showing electron temperature, plasma density, and plasma beta. The vertical dashed lines indicate the onset of the dipolarization associated with the flow disturbances.

downward FAC (Figure 6, bottom left panel). The first negative then positive $\mathrm{Vz}$ disturbance suggests a motion of this pattern (dashed arrow), which is consistent with an eastward expansion of the azimuthally aligned arc. The disturbance was first encountered by TH-E and then TH-D, carried downward FAC, and represented the dawnward part of a large earthward flow. Most likely there was an upward FAC further to the west that connected to the auroral activity seen on the ground.

[22] The similar flow and magnetic field signatures at TH-E and TH-D suggest that both spacecraft encountered disturbances associated with the same activation. The dis- turbances at TH-E preceded those at TH-D, indicating equatorward/eastward propagation of the disturbance.

\subsection{Optical Flow Analysis}

[23] The small-scale substructures in the poleward arc1 and their motions were visible in the all-sky images. However, the small-scale folded auroral sub-structure in arc2 was only seen in the Reimei data since in the all-sky image data the smallscale structures would be degraded due to the overlap of auroral emissions along the line-of-sight direction toward the edge of the FoV. The dynamics of the large-scale auroral 


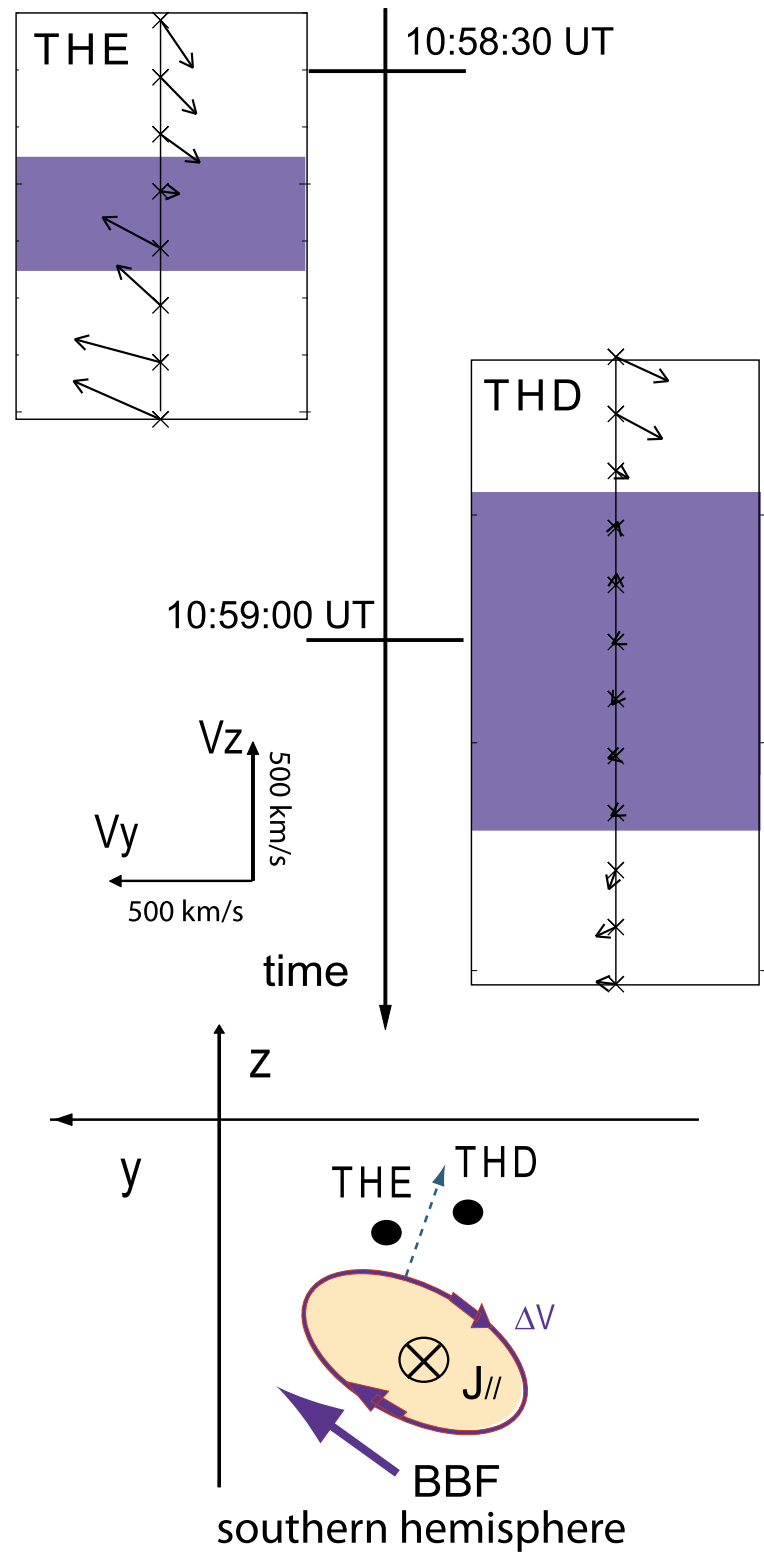

Figure 6. Flow disturbance perpendicular to the magnetic field at TH-D and TH-E in the GSM Y-Z plane. Time proceeds in the downward direction. The time interval with colored background is the dipolarization interval. The possible field-aligned current configuration as determined from velocity disturbances is illustrated at the bottom.

expansion in the poleward and east-west directions can be revealed from the mosaic images after 1059 UT.

[24] In order to analyze the auroral small-scale motions we used the method of optical flow analysis as described earlier. The INUV all-sky images were first mapped into equal area geographic projections and then two frames ( $3 \mathrm{~s}$ apart) were analyzed to determine the speed and direction of small-scale motions. Figure 7 shows an example for the two frames of 1058:15 and 1058:18 UT. Several small-scale structures can be recognized in both arcs and their motion is given in two ways, as flow vectors drawn for selected points within the image and as the color coded magnitude of the east-west motion. The red regions at the poleward edge of the arc show eastward motion with an average value of $5.5 \mathrm{~km} / \mathrm{s}$ (range 3 $8 \mathrm{~km} / \mathrm{s}$ ). The blue areas at the equatorward edges of the arcs mark westward motions with an average of $1.3 \mathrm{~km} / \mathrm{s}$ (range $0.4-3.0 \mathrm{~km} / \mathrm{s}$ ). The average north-south motion (not shown) was more then an order of magnitude smaller.

[25] There were significant shear flows along arc1 in the Reimei images, as presented in the optical flow analysis plot in Figure 8. Strong westward flows were dominant in the equatorward and westward sides of the arc. In addition, there were eastward flows in the poleward and eastward sides. Note the much smaller FoV and time difference between images compared to the analysis using the all-sky images (Figure 7). The flow speeds were in the range from 5 to $15 \mathrm{~km} / \mathrm{s}$, with typical speeds of $\sim 10 \mathrm{~km} / \mathrm{s}$. The shear flow direction is consistent with the model explaining it in terms of the $\mathrm{E} \times \mathrm{B}$ drift [Hallinan, 1981] inside the inverted- $\mathrm{V}$ potential drop [Haerendel et al., 1996]. The asymmetry of the flow within the arc suggests that the potential structure may have been S-shaped.

\subsection{Reconstruction of Current Systems}

[26] The evolution of the ionospheric equivalent currents is shown in Figure 9. The dots in Figure 9 show the locations at which ionospheric equivalent currents were calculated and from which the current vectors originate. Note that the grid of these locations is irregularly shaped, following the availability of ground magnetometer stations. The analysis area covers the region from $\sim 23$ to 07 MLT.

[27] About 20 min before our event, at 1039 UT, a fairly uniform westward electrojet is seen over the whole analysis area, centered at $\sim 62^{\circ}$ latitude in central Canada and at $\sim 68^{\circ}$ in Alaska, and intensifying toward the western part of the area under study (magnetic midnight is located in Eastern Alaska). The maximum current densities reached $\sim 200 \mathrm{~mA} / \mathrm{m}$ (Figure 9a). From here on, the current densities over Alaska constantly decreased, reaching only $\sim 50 \mathrm{~mA} / \mathrm{m}$ at $1057 \mathrm{UT}$. On the other hand, the currents in the early morning and morning sector (in central Canada and up to Greenland) were much less affected and only decreased slightly (Figure 9b, 1057:00 UT).

[28] At about 1057:30 UT, a clear anticlockwise ionospheric equivalent current vortex started to develop in the magnetic midnight sector, which quickly intensified until 1102 UT, reaching current densities of more than $600 \mathrm{~mA} / \mathrm{m}$ at its northern flank (Figure 9c). Since no signs of eastward motion at the westward border of the analysis area are seen, we did not deal with an intrusion of a substorm bulge that had its breakup westward of our analysis region. Instead the breakup occurred close to magnetic midnight in the area under observation (see Figure 2). Previous observations indicate that the breakup area is a region where ionospheric conductance gradients roughly point along the electric field [e.g., Baumjohann et al., 1981; Amm et al., 2002]. Therefore, around the breakup vortex it is possible to estimate the FAC from the curl of the ionospheric equivalent currents. In this case, the anticlockwise equivalent current vortex corresponded to a region of upward FAC, which was fed by a region of downward FAC north- and northeastward of the vortex.

[29] Even though the temporal variability of the ionospheric equivalent currents remained high and several shortlived disturbances were seen, the currents mostly formed a 

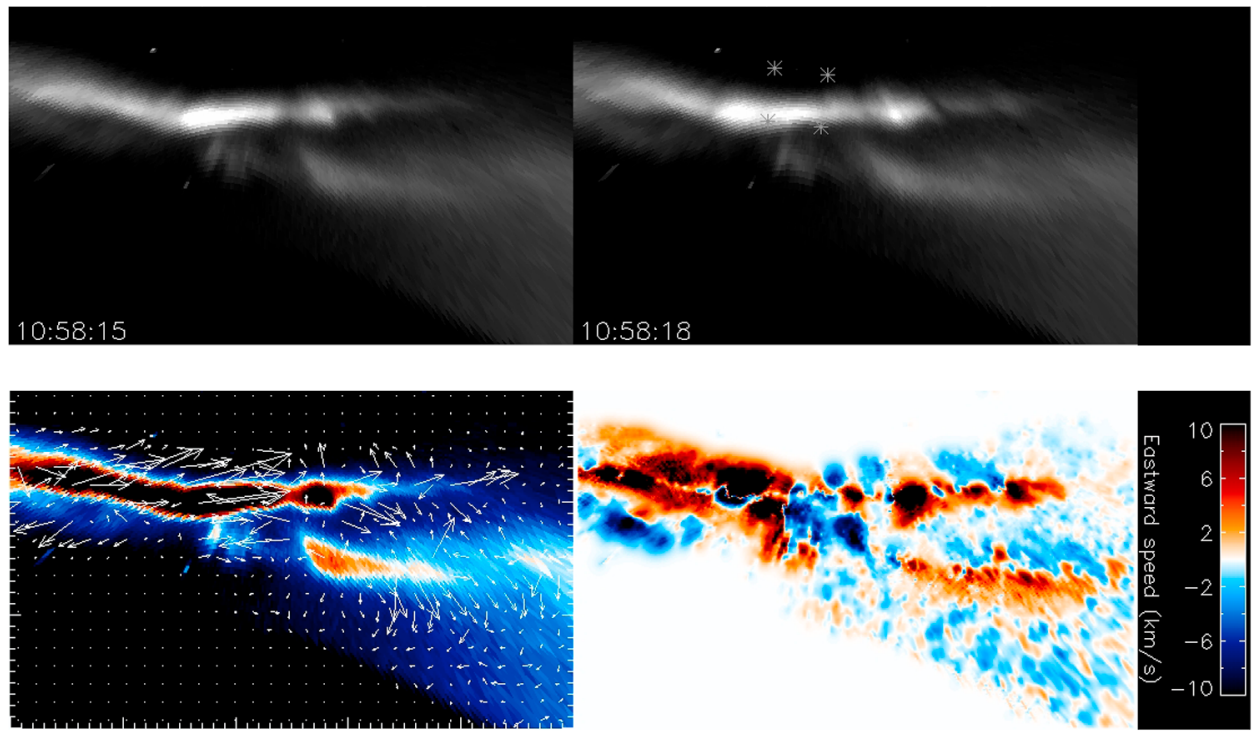

Figure 7. Results of the optical flow analysis between the two Inuvik images (top) from 1058:15 and 1058:18 UT. (top right) The Reimei FoV at that time. (bottom left) The 1058:15 UT image with several flow vectors over plotted. (bottom right) The east-west component of motion with regions moving eastward shown in red and those moving westward shown in blue.

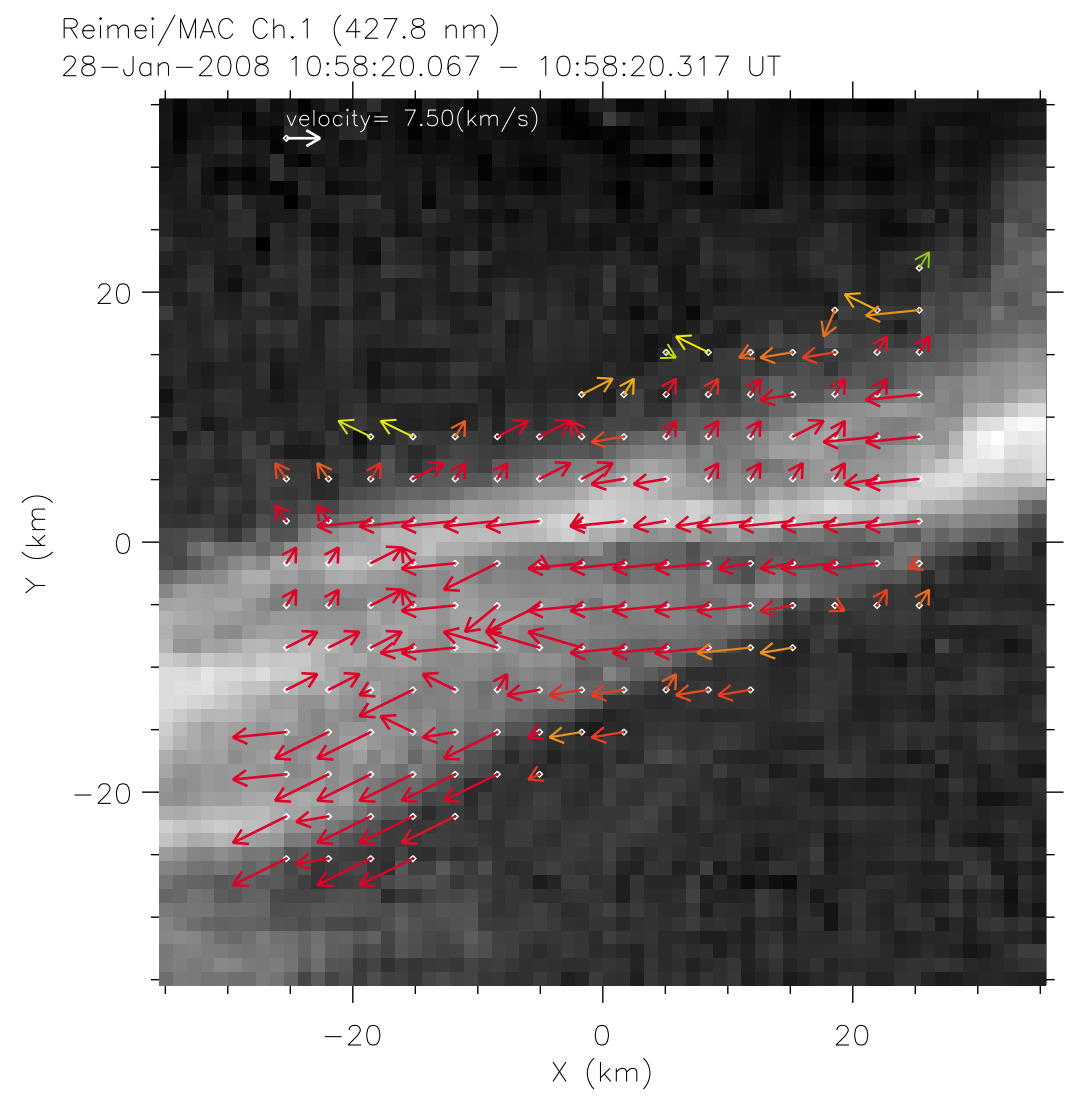

Figure 8. Example of optical flow analysis performed on the poleward intense arc1 using Reimei images. The warm color indicates that the error in the $2 \mathrm{D}$ correlation is relatively small, whereas the cold color represents areas with relatively large errors. 
(a)

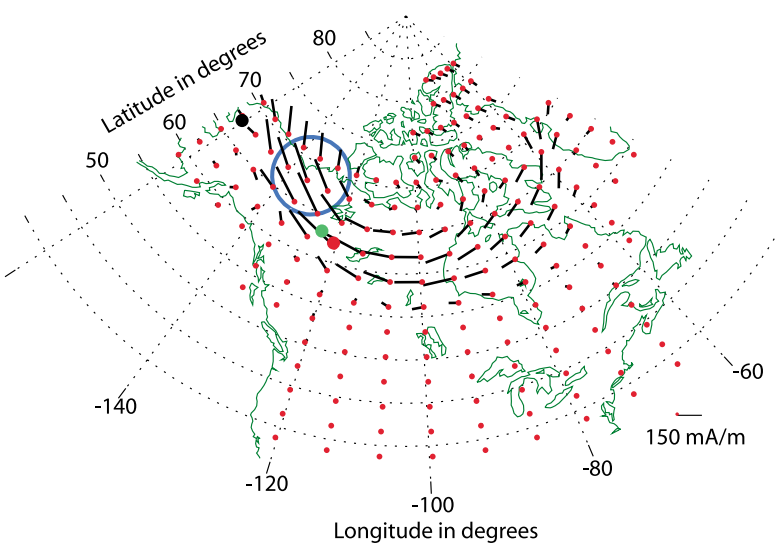

(c)

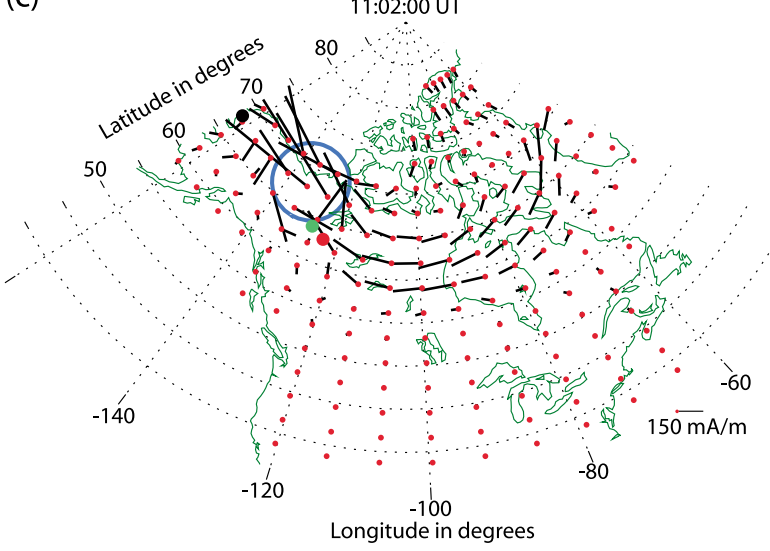

(b)

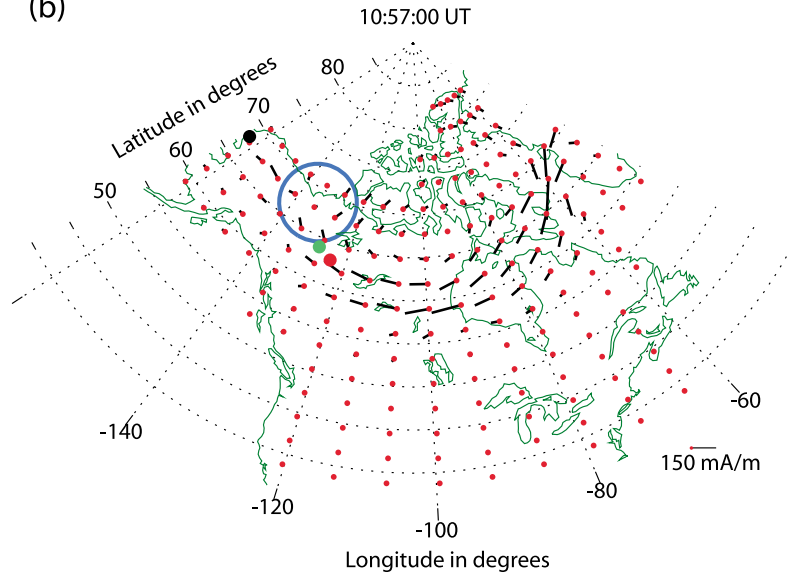

(d)

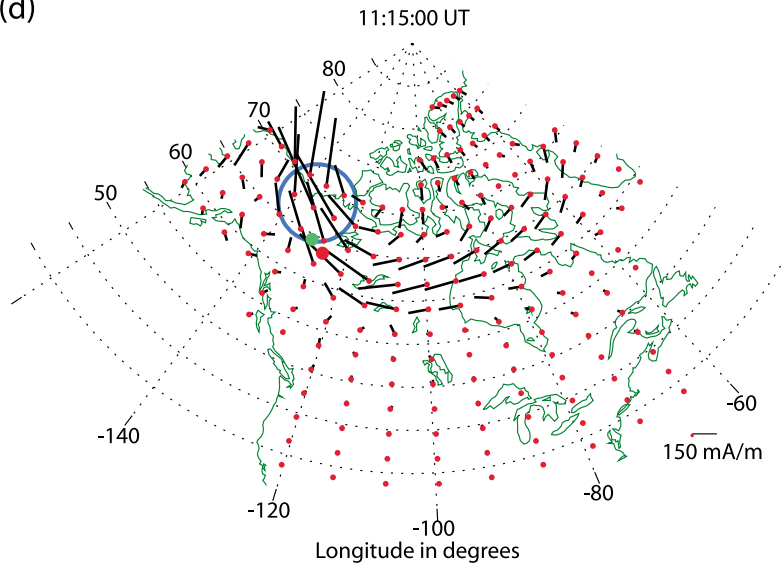

Figure 9. Ionospheric equivalent currents during the development and breakup of the auroral arc. (a) 1039, (b) 1057, (c) 1102, and (d) 1115 UT are shown during the substorm growth phase, shortly before and after breakup, and during the main substorm expansion. The field of view of the Inuvik all-sky camera is given together with the magnetic footprints of three THEMIS spacecraft.

straight electrojet again at $1115 \mathrm{UT}$ at higher latitudes than the electrojet before the event (Figure 9d). Further on, the electrojet became less intense and its maximum shifted equatorward, reaching about the latitude as before the event at 1125 UT. Thus, due to the short temporal scale of the event ( $\sim 25 \mathrm{~min})$, the localized MLT sector that it affected $(\sim 2 \mathrm{~h}$ MLT), and the rather small maximum pseudo-AE index of $500 \mathrm{nT}$ (Figure 1), this event can only be categorized as a small substorm.

\subsection{Estimating the Precipitating Energy Flux}

[30] The combination of particle data and near simultaneous optical measurements at $427.8 \mathrm{~nm}\left(\mathrm{~N}_{2}^{+}\right)$provides a means for estimating the energy flux of the precipitation. From this spectral line it can be assumed that the emission rate is proportional to the total energy flux [Rees and Luckey, 1974]. This is particularly important to the study of the brightest features within arc1 which are driven by electrons with energies above the upper limit of the electron detector.

[31] The particle data for arc1 have the general shape of an inverted-V distribution, with some structuring at the leading edge. Optically, arc1 exhibits internal structure which appears like a rope inside the total width, with this core having a brighter intensity (Figure 8). The high energy center of the arc was not measured by Reimei electron detectors with their cut- off at $12 \mathrm{keV}$. Arc 2 can be seen in Figure 3 as a folding arc, with lower optical intensity, and with peak energies of less than $10 \mathrm{keV}$, fully measured by Reimei.

[32] For arc1, the Reimei particle measurements were made when the arc was just outside of the camera FoV to the south, which means that the Reimei cameras view arc1 about $10 \mathrm{~s}$ after Reimei has measured the particles. For arc2, however, the Reimei footprint coincided in time with both the optical and particle data. Therefore there are three main factors which could cause the estimate of energy flux to be uncertain. (a) There is a timing difference between the particle and optical measurements from Reimei of about $10 \mathrm{~s}$ in arc1. (b) There are missing high energies in the main region of arc1. (c) The effect of extra light sources (contamination) in Reimei optical data needs to be estimated.

[33] The changes in brightness during the $10 \mathrm{~s}$ between particle and optical measurements have been studied using the all-sky camera data. It has been estimated that for arc1 there was about a $20 \%$ increase in brightness (in white light) in this $10 \mathrm{~s}$ interval, such that the particle data were measured at a time when the arc was less bright than the optical measurements made of arc1 $10 \mathrm{~s}$ later.

[34] The auroral model used in this work is a timedependent model which solves the electron transport equation, the coupled continuity equations for all important 

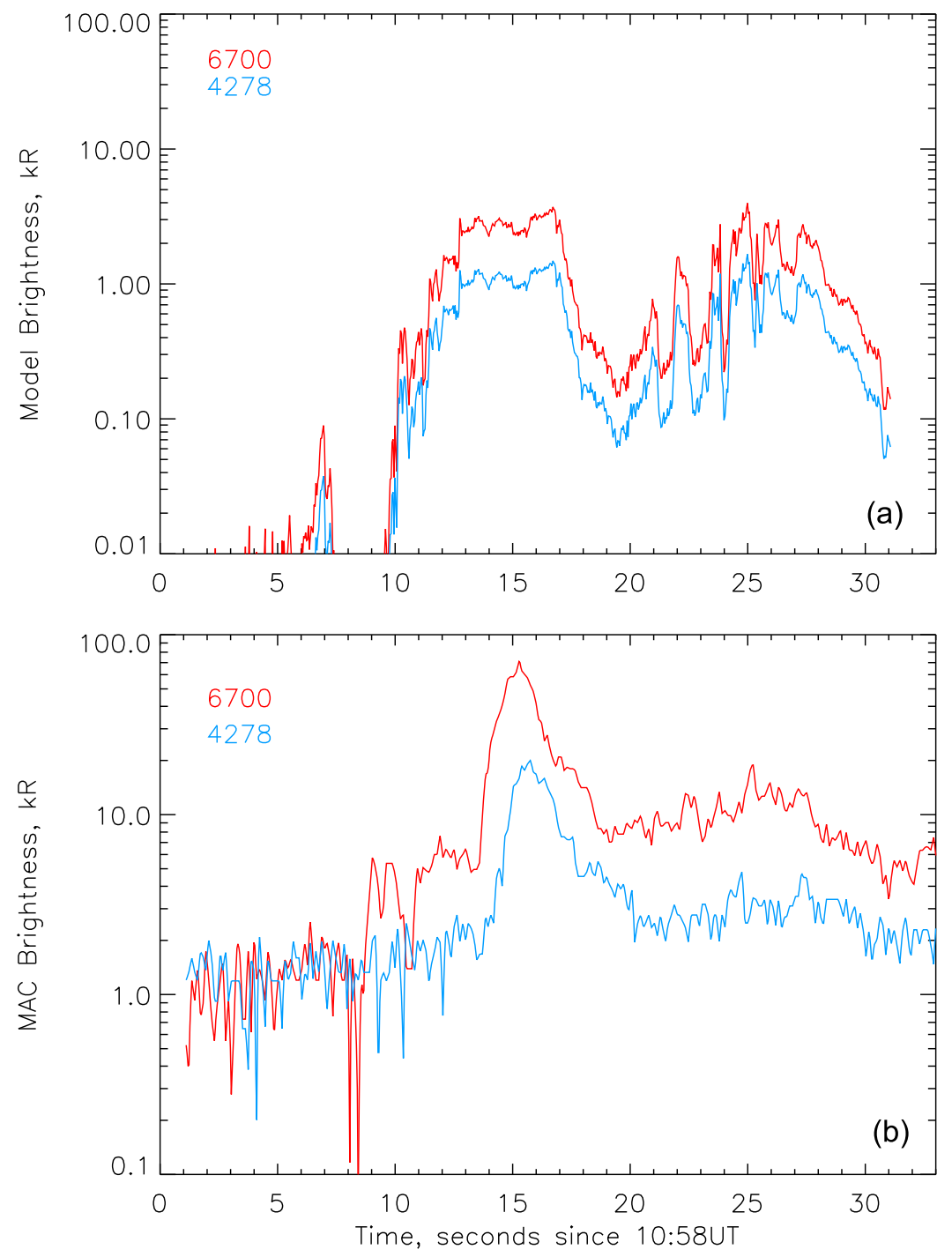

Figure 10. (a) Model brightness of $427.8 \mathrm{~nm}$ and $670 \mathrm{~nm}$ emissions resulting from using Reimei particle spectra as input as the satellite crossed arc1 and arc2. (b) Estimated brightness from MAC instruments on Reimei during the same time interval.

positive ions and minor neutral species, and the electron and ion energy equations. The neutral atmosphere is taken from the MSIS-90 thermospheric model [Hedin, 1991]. The main input required is an estimate of the shape and peak energy of the electron energy spectrum at each time step, and the magnitude of the precipitation energy flux. Other inputs are electron impact cross sections of the major atmospheric neutral constituents. Cross sections for excitation and the energy losses of each individual excited state are required to calculate the energy degradation, and the resulting emission profiles. These profiles are then integrated to give surface brightness. The multistream solution of the electron transport equation has updated cross sections and energy grid from Lummerzheim and Lilensten [1994]. Details of the ion chemistry can be found from Lanchester et al. [2001].

[35] The results of running the auroral model using Reimei electron spectra as input are shown in Figure 10a. The model gives the brightness of both the $427.8 \mathrm{~nm}$ emission from $\mathrm{N}_{2}^{+}$ $(1 \mathrm{~N})$ and the $670 \mathrm{~nm}$ emission from the $\mathrm{N}_{2} 1 \mathrm{P}$ band, taking into account the Reimei filter transmission [Obuchi et al.,
2008]. For comparison, in Figure 10b are the measured brightnesses for these two emissions. Two features are seen in this comparison. First, there is a clear discrepancy during the interval centered on $15 \mathrm{~s}$ after $1058 \mathrm{UT}$, when the Reimei particle data were limited by the cut-off at $12 \mathrm{keV}$. As well, the $10 \mathrm{~s}$ difference in timing between particle and optical data could be giving optical estimates of brightness $20 \%$ above the particle estimates. The model therefore underestimates the brightness in this interval on both counts. The other difference is seen in the results for arc2. The measured brightness of $427.8 \mathrm{~nm}$ is approximately $3 \mathrm{kR}$, whereas the model produces about $1 \mathrm{kR}$. This difference is entirely due to the effects of light contamination. At the time of observation the Moon was $66 \%$ of full and located at $6^{\circ}$ elevation and $143^{\circ}$ azimuth and the majority of the light contamination comes from scattered moonlight from the ground plus some aurora reflection from the snow cover.

[36] Figure 11 demonstrates how the model results can be used to provide information about the contamination, and also provide a correction for the missing high energy flux in 


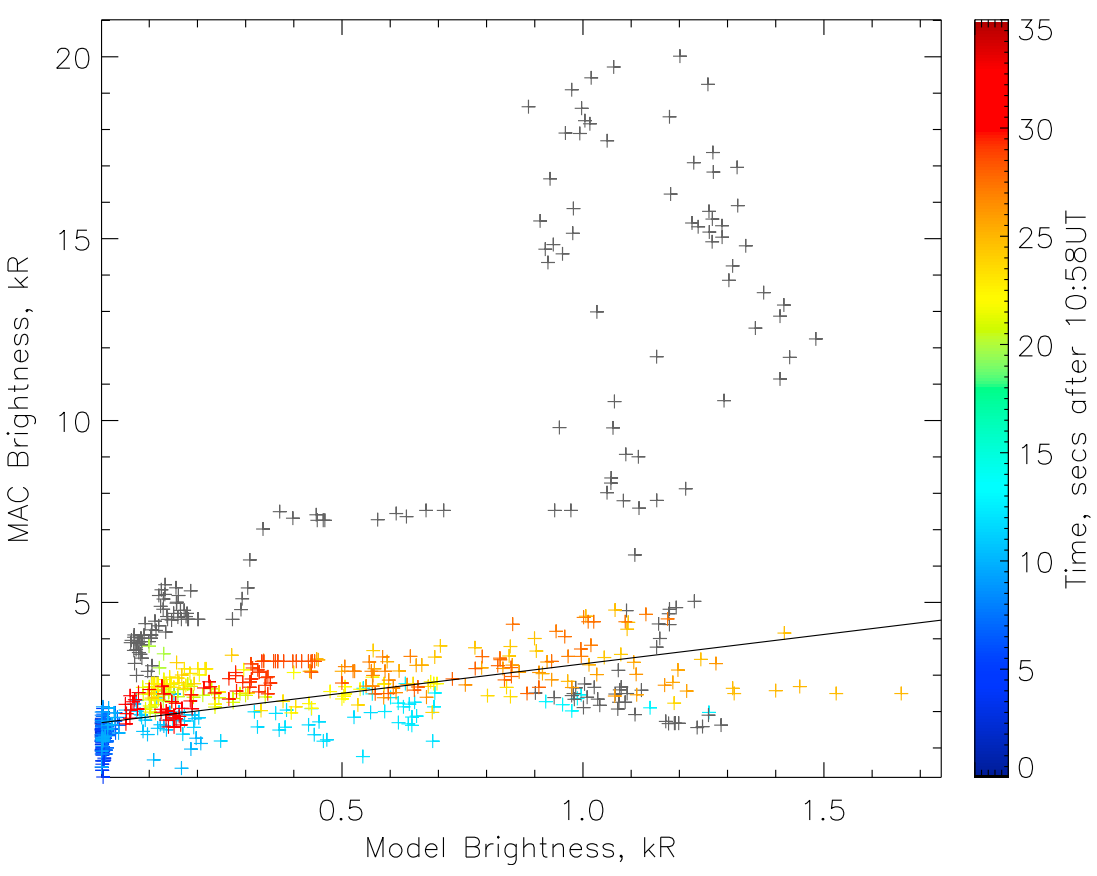

Figure 11. Estimated brightness of $427.8 \mathrm{~nm}$ emission from MAC instrument plotted against the modeled brightness. Grey points are obtained during the time of missing high energies in the particle data, and thus in the model data. All data apart from the grey points are fitted to the line drawn, the slope of which gives an estimate of light albedo as a function of brightness. The intercept gives an estimate of the background light contamination.

the center of arc1. In Figure 11 measured brightnesses of $427.8 \mathrm{~nm}$ are plotted against model results for this emission. The color coding represents time in seconds after 1058 UT. The gray points correspond to the times of the missing high energy tail between 1058:13-17 UT. All non-gray points have been fitted to find the slope and the offset of the data for which measured and modeled results should correspond (mostly in arc2, but also at the edges of arc1). The offset of $1.69 \mathrm{kR}$ therefore corresponds to the background brightness and the slope of 1.61 to the variable albedo. The latter variability means that as the aurora brightens so does the light reflected from the snow on the ground. The value of $61 \%$ is an acceptable value for snow albedo below $500 \mathrm{~nm}$ [Wuttke et al., 2006]. Using these values, all data points have been converted to new values of brightness, accounting for the extra light sources. The gray points will then lie on the extension of the line of best fit at large values of brightness (3-10 kR) corresponding to the correct particle flux in arc1.

[37] The model results can be used to give a conversion of $427.8 \mathrm{~nm}$ brightness to energy flux. Figure 12 shows model brightnesses for an input energy flux of $1 \mathrm{~mW} / \mathrm{m}^{2}$ for Gaussian energy spectra with peak energies between $30 \mathrm{eV}$ and $30 \mathrm{keV}$. This graph can be scaled to give energy fluxes corresponding to the corrected brightnesses, folding in the slight energy dependence. For comparison model results are shown for the $670 \mathrm{~nm}$ emissions, which are also related to the energy flux. The ratio of these two emissions is found to be in good agreement with the corrected values, with a near constant ratio with energy.

[38] Finally, in Figure 13 the now 'calibrated' variations in brightness and energy flux are plotted as a function of time as
Reimei crosses both arcs. This method relies on interpreting the temporal changes as spatial changes, thus assuming that the two arcs did not move during the passage of the satellite (see Figure 1 (bottom)). We estimate that an average flux of $\sim 25 \mathrm{~mW} / \mathrm{m}^{2}$ goes into the main arc of about $25 \mathrm{~km}$ width. However, the width of the narrow rope-like structure (energy flux $>40 \mathrm{~mW} / \mathrm{m}^{2}$ ) is probably as narrow as a few $\mathrm{km}$. The region of current flow in and out of the ionosphere corresponds to a wider region, and if the region of arc 2 is included, that width is around $100 \mathrm{~km}$.

\section{Theory}

\subsection{Quantitative Comparison With Theory}

[39] The event of 28 Jan 2008 can be characterized as the brightening of the growth phase and substorm onset arc. The Reimei passage occurred just at the time of onset, and good coverage exists with the THEMIS GBO network. This is precisely the situation for which Haerendel [2009] developed a theoretical framework. Since only a very limited number of parameters were measured, a true consistency check of the theory is hardly possible. But it is tempting to see what can be deduced about this event from the measured parameters which are:

Average energy flux into the arc:

$$
\dot{\mathbf{W}}_{\text {arc }}=25 \mathrm{~mW} / \mathrm{m}^{2}
$$

Mean electron energy:

$$
<\mathbf{W}_{e l}>=10 \mathrm{keV}
$$




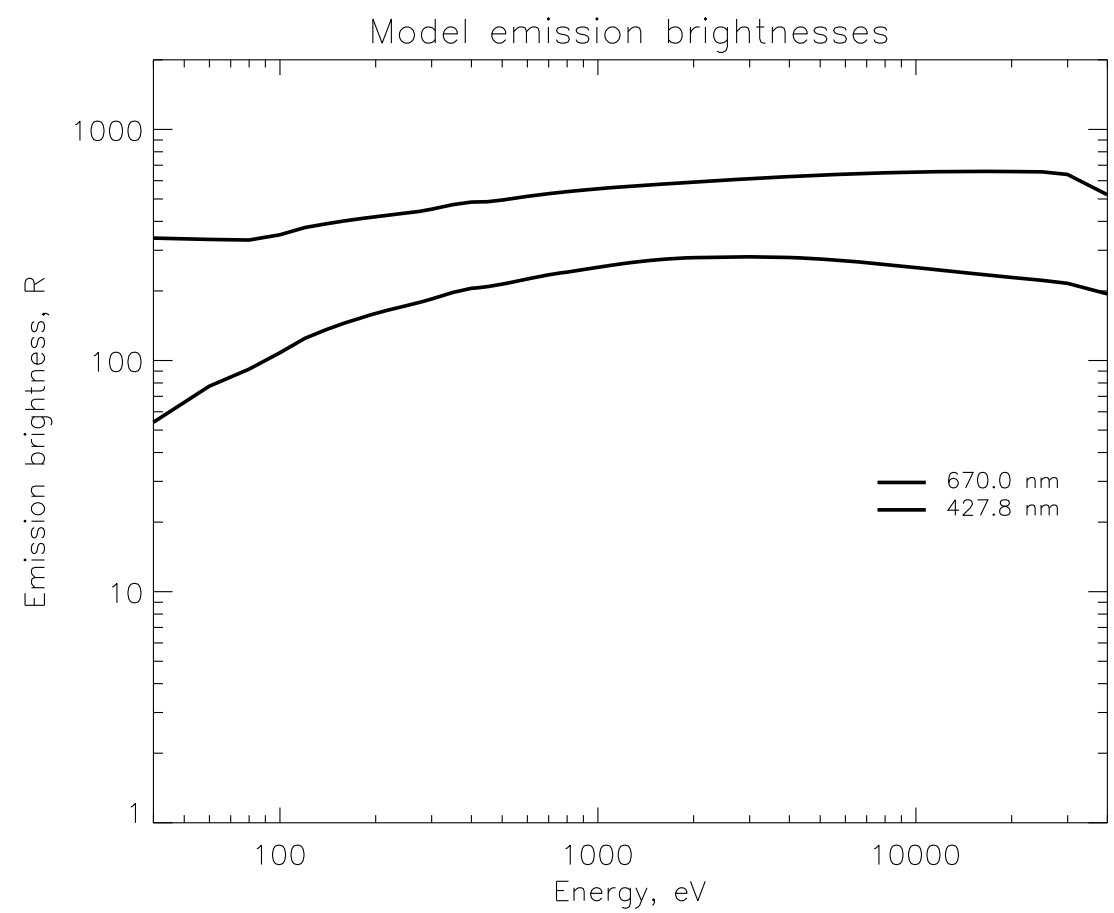

Figure 12. Model results of the variation of brightness with peak energy for a Gaussian shaped spectrum using an input flux of $1 \mathrm{~mW} / \mathrm{m}^{2}$. This graph is used to convert brightness to energy flux.

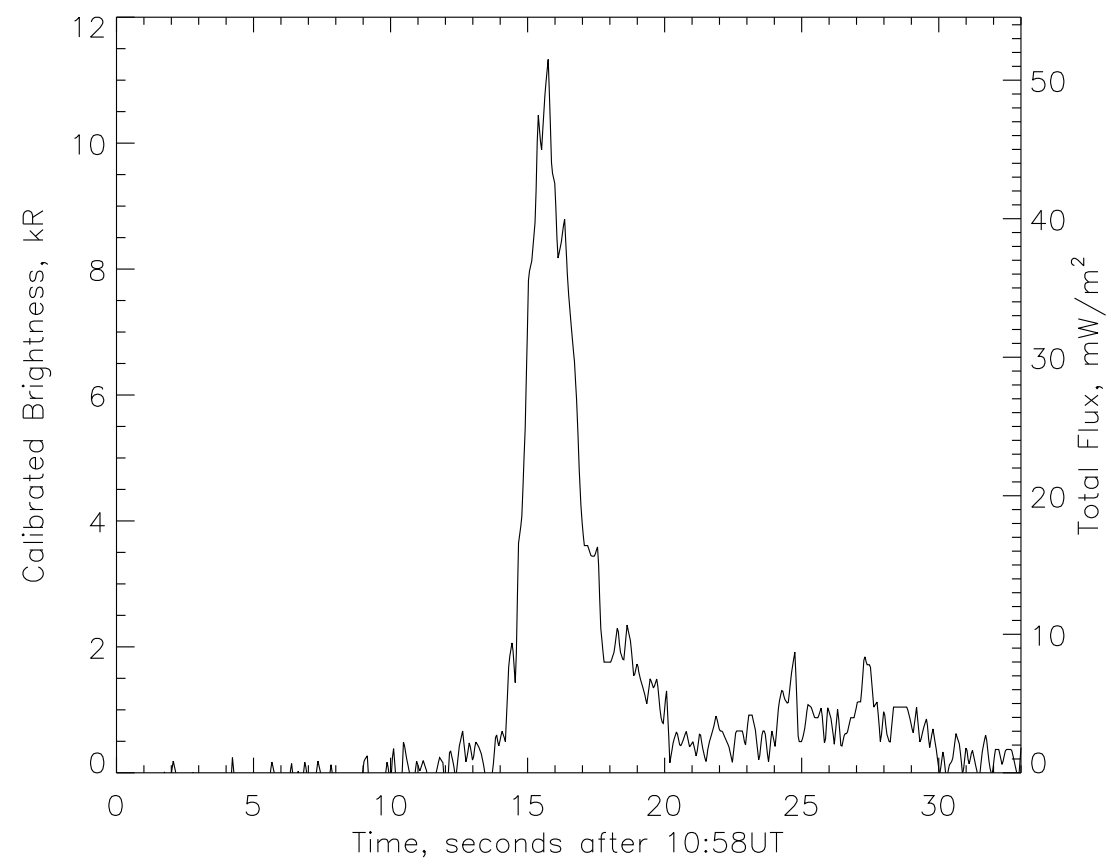

Figure 13. Calibrated brightness of $427.8 \mathrm{~nm}$ emission for the passage of Reimei across both $\operatorname{arc} 1$ and arc2. The right-hand axis gives the corresponding energy flux. 
Width of arc:

$$
\mathbf{w}_{\text {arc }}=25 \mathrm{~km}
$$

Width of inverted-V event:

$$
\mathbf{w}_{\mathrm{InV}}=65 \mathrm{~km}
$$

Electron temperature at TH-E:

$$
\mathbf{T}_{\mathrm{e}}=1.5 \mathrm{keV}
$$

Electron density at TH-E:

$$
\mathbf{n}_{\mathrm{eH}}=0.25 \mathrm{~cm}^{-3}
$$

Fold speed along arc:

$$
\mathbf{v}_{\mathrm{F}}=4-7 \mathrm{~km} / \mathrm{s}
$$

Magnetic perturbation field nearby:

$$
\Delta \mathbf{B}_{\mathbf{x}}=-30 \mathrm{nT}
$$

[40] The importance of the first four parameters is obvious. Electron temperature and density of the generator plasma define the theoretical field-aligned conductance in the auroral acceleration region according to the theory of Knight [1973]. A bursty bulk flow (BBF) event is observed at TH-E starting almost coincident with the auroral breakup. At the same time, electron density and temperature change. It seems more likely that the electron properties before the BBF apply to the source region of the auroral current. They are listed above. The conductance calculated on the basis of these parameters will serve as a consistency check with the conductance derived from the measured auroral parameters. The drift speed of the small luminosity structures is a proxy for the transverse electric field in and above the acceleration region. Finally, based on an optimization argument, we will show that the theory produces the characteristics of the auroral electrojet flowing along the arc and theoretical magnetic perturbations in the area.

[41] The differentiation between arc width and the width of the inverted-V structure of the particle flux needs explanation. The spectrogram of Figure 4 shows a central energy reaching above the experimental cut-off with average electron energy $\left\langle W_{e l}\right\rangle$ near $10 \mathrm{keV}$, which we adopt as model input. The inverted- $\mathrm{V}$ exhibits a drastic energy drop on either side of the central flux. This has the consequence that the visible arc assumes the width of that central flux while the emission falls off drastically outside. The theory underlying the poleward arc model does not resolve the arc structure and operates with quantities averaged over the width of the electromagnetic energy flux or upward field-aligned current region. Observationally, the latter has to be identified with the inverted-V.
[42] In the following the differentiation between local and average quantities will be important. From the central energy flux and mean electron energy we can derive the magnitude of the field-aligned current density, since these electrons are the carriers of the upward current:

$$
\mathbf{j}_{\|}=\mathrm{e} \frac{\dot{W}_{\text {arc }}}{<W_{e l}>}=2.5 \times 10^{-6} \mathrm{~A} / \mathrm{m}^{2}
$$

The field-aligned sheet current density, including a $10 \%$ addition from the current outside the central energy flux, is:

$$
\mathbf{J}_{\|} \approx 1.1 \times \mathbf{j}_{\|} \mathrm{w}_{\mathrm{arc}}=0.07 \mathrm{~A} / \mathrm{m}
$$

The Poynting flux, $S$, within an Alfvén wave or inside a quasi-static current system can be expressed by $J_{\|}$and the wave impedance $\mathrm{R}_{\mathrm{w}}$ [Haerendel, 2009]:

$$
\boldsymbol{S}=\boldsymbol{R}_{w} \boldsymbol{J}_{\|}^{2}
$$

The theoretical energy flux is an average over the whole inverted-V. Therefore, we smear $\dot{W}_{\text {arc }}$ over the width of the inverted- $\mathrm{V} \mathrm{w}_{\mathrm{InV}}$ which gives approximately $S=12.5 \mathrm{~mW} / \mathrm{m}^{2}$. From equation (3) we obtain $\mathrm{R}_{\mathrm{w}}=2.5 \mathrm{ohm}$. This can be checked against the definition of the integrated wave impedance by Haerendel [2009]:

$$
\boldsymbol{R}_{\boldsymbol{W}}=\frac{\mu_{0} R_{E} L}{\tau_{A} \Gamma^{2}}
$$

by solving for the Alfvénic transit time from the generator to the ionosphere, $\tau_{\mathrm{A}}$. $\mathrm{R}_{\mathrm{E}}$ is the Earth's radius and $\Gamma^{2}=1.21 \mathrm{a}$ dimensionless constant. For the $\mathrm{L}$-value of the source region we adopt the location of the TH-E spacecraft, because we derive the characteristics of the generator plasma from there. Of course, there is considerable uncertainty connected with $\mathrm{L}$. It could be smaller or greater, most likely smaller, as the inner boundary of the tail, where the current generator is likely to be found, can approach the Earth to distances below $8 \mathrm{R}_{\mathrm{E}}$. Inserting $\mathrm{L}=11$ we obtain $\tau_{\mathrm{A}}=32 \mathrm{~s}$ and for $\mathrm{L}=8$ we get $\tau_{\mathrm{A}}=$ $23 \mathrm{~s}$. Taking density and magnetic field as measured at TH-E $(B=20 \mathrm{nT})$ we find an Alfvén velocity of about $870 \mathrm{~km} / \mathrm{s}$. With an extent of the generator plasma of no more than $3 R_{E}$, $\tau_{\mathrm{A}}$ would be estimated to be somewhat above $22 \mathrm{~s}$. Thus we may conclude that the derived value for $\mathrm{R}_{\mathrm{W}}$ is quite realistic. This can be traced to our estimate of $J_{\|}$, in which we neglected the current contribution at the fringes of the inverted-V.

[43] If the accelerating potential, $U$, and the voltage equivalent of the magnetospheric electron temperature, $V_{0}=$ $\mathrm{e}^{-1} T_{e, \|}$, are close to each other, the current-voltage relation and the corresponding flux-voltage relations are [Fridman and Lemaire, 1980]:

$$
\begin{gathered}
j_{\|}=K \cdot U \\
\dot{\boldsymbol{W}}_{\text {arc }}=\mathrm{K}\left(\mathrm{U}^{2}+2 \mathrm{UV}_{0}\right)
\end{gathered}
$$

With $\mathrm{U}=\mathrm{e}^{-1} \mathrm{~W}_{\mathrm{el}, \max }-\mathrm{V}_{0}=8.5 \mathrm{kV}$ one obtains from equation (5) $\mathrm{K}=2.94 \times 10^{-10} \mathrm{~S} / \mathrm{m}^{2}$ and from equation (6) $\mathrm{K}=$ $2.55 \times 10^{-10} \mathrm{~S} / \mathrm{m}^{2}$. Both values are well within the range of experiments [Persoon et al., 1988; Haerendel, 1999]. The 
theoretical value [Knight, 1973], based on $\mathrm{n}_{\mathrm{e}}=0.25 \mathrm{~cm}^{-3}$ and $\mathrm{c}_{\mathrm{th}, \mathrm{el}}=1.63 \times 10^{9} \mathrm{~cm} / \mathrm{s}\left(\mathrm{T}_{\mathrm{e} \|}=1.5 \mathrm{keV}\right)$, yields:

$$
K=\frac{e^{2} n_{e}}{\sqrt{\pi} m_{e} c_{t h, e l}}=2.4310^{-10} \mathrm{~S} / \mathrm{m}^{2}
$$

This is an excellent agreement. Furthermore, it is interesting to see, what width is given for the arc by the theoretical relation of Haerendel [2009] with $\mathrm{R}_{\mathrm{W}}$ as above and for $\mathrm{K}$ with the mean value of $2.75 \times 10^{-10} \mathrm{~S} / \mathrm{m}^{2}$ :

$$
\mathrm{w}_{\text {arc }}=\left(\mathrm{R}_{\mathrm{w}} \mathrm{K}\right)^{-1 / 2}=40 \mathrm{~km}
$$

It is quite satisfactory that this width lies between the width of the arc proper and the inverted- $\mathrm{V}$, because $\mathrm{K}$ is applying to the first and $\mathrm{R}_{\mathrm{W}}$ to the latter system.

[44] A final comparison is possible with the observed small-scale drift speed. The typical electric field in and above the acceleration region, as expressed by the ray or fold motions along the arc [Davis, 1978; Haerendel et al., 1996], is:

$$
E_{\perp}=\frac{2 U}{\mathrm{w}_{\mathrm{InV}}}
$$

Here it is appropriate to use the width of the inverted-V structure, since it carries the electromagnetic energy flux. These numbers yield $E_{\perp}=254 \mathrm{mV} / \mathrm{m}$ or a fold velocity of $5 \mathrm{~km} / \mathrm{s}$. This lies well within the range as determined from the Reimei and all-sky images. Haerendel [2007] interprets these apparent flows as stress release motions of the sheared magnetic field in and above the acceleration region of a slowly propagating arc. The observed asymmetry between the poleward and equatorward flows (section 3.4) suggests that the propagation is directed poleward relative to the plasma frame. In summary we can say that the comparison with theory did not produce any unreasonable results.

[45] Unfortunately, Reimei has neither electric nor magnetic field detectors on board. But observed fold speeds and ground magnetometer reading provide some tools for comparison. To this end, we first determine the conductivities in the auroral arc, which carries the auroral electrojet. We use the empirical expressions of Robinson et al. [1987]:

$$
\mathrm{s}=\frac{\Sigma_{H, a r c}}{\Sigma_{P, a r c}}=0.45 \tilde{\Phi}^{0.85} \text { with } \tilde{\Phi}=\left(\mathrm{U}+\mathrm{V}_{0}\right) / 1 \mathrm{kV}
$$

and

$$
\Sigma_{\mathrm{p}, \mathrm{arc}}=40 \mathrm{~S} \frac{\tilde{\Phi}}{\left(16+\tilde{\Phi}^{2}\right)} \sqrt{\frac{\dot{\boldsymbol{W}}_{\text {arc }}}{1 \mathrm{~mW} / \mathrm{m}^{2}}}
$$

We find for the ratio of Hall and Pedersen conductivity: $\mathrm{s}=3.19$, a rather high value thanks to the deep penetration of the $\sim 10 \mathrm{keV}$ electrons into the ionosphere, and finally $\Sigma_{\mathrm{P}}=17.2 \mathrm{~S}$.

[46] Inspection of the magnetograms showed that the negative bay developing with the activation of the arc had a relatively short extent in local time. This could lead to the conclusion that we did not have a Boström [1964] Type-I current system, as normally assumed for the substorm current wedge, but rather a Type-II system. The ion distributions measured by Reimei before meeting the arc (Figure 4) showed downward and transverse fluxes up to about $100 \mathrm{eV}$, coincident with an almost complete absence of electrons. This suggests that a region poleward of the inverted- $\mathrm{V}$ of about $40 \mathrm{~km}$ width contained a downward current carried by upward accelerated ionospheric electrons and is connected by equatorward Pedersen currents to the upward current inside the inverted-V. However, the magnitude of this downward current is unknown and, therefore, the contribution of a Type II current.

[47] If there was a pure Type II system, the Pedersen current would equal the field-aligned sheet current. That would lead to:

$$
\mathrm{E}_{\mathrm{xi}}=\Sigma_{\mathrm{p}}^{-1} \boldsymbol{J}_{\|}
$$

and a southward electric field of $E_{x i}=-4.3 \mathrm{mV} / \mathrm{m}$. The current causing the ground-based magnetic perturbations is the Hall current:

$$
\mathrm{J}_{\mathrm{H}}=\mathrm{s} \Sigma_{\mathrm{p}} \mathrm{E}_{\mathrm{xi}}=\mathrm{s} \boldsymbol{J}_{\|}
$$

At the time of the Reimei passage the height-integrated Hall current density was about $0.24 \mathrm{~A} / \mathrm{m}$. Multiplied by the arc width $(25 \mathrm{~km})$ this density yields a total current of $6 \mathrm{kA}$. At the position of the nearest magnetometer, i.e., Inuvik, one should have registered a negative horizontal perturbation field of $-8.3 \mathrm{nT}$ at the time of Reimei passage. The actual readings were closer to $-30 \mathrm{nT}$. This may be due to the neglected contributions from the wider inverted-V plus arc2 or be caused by a Type-I current contribution, i.e., by the presence of a westward electric field and enhanced Hall current as in the model of Haerendel [2009]. If the latter applied, the missing $22 \mathrm{nT}$ at Inuvik would require a total Hall current of about $16 \mathrm{kA}$ or a sheet current of $0.64 \mathrm{~A} / \mathrm{m}$. The above figures for $\mathrm{s}$ and $\Sigma_{\mathrm{P}}$ imply a westward electric field of $3.33 \mathrm{mV} / \mathrm{m}$ and an additional southward polarization field of $-10.6 \mathrm{mV} / \mathrm{m}$. With the contribution from the Type II Pedersen current, the total southward field would have been $\mathrm{E}_{\mathrm{xi}}=-14.9 \mathrm{mV} / \mathrm{m}$ corresponding to an eastward plasma drift of nearly $300 \mathrm{~m} / \mathrm{s}$. Since the additional southward Pedersen current is almost completely balanced by the northward Hall current, the upward field-aligned current is practically unchanged, whereas the ionospheric dissipation is greatly enhanced [Haerendel, 2009]. In summary, it appears that the situation is similar to those analyzed by Marghitu et al. [2004, 2009] where Type I coupling between field-aligned current and electrojet is connected with a Type II system.

\subsection{Arc Structuring and Stability}

[48] The electro-dynamic model described in the previous section provides a self-consistent description of the mesoscale properties of the onset arc we identify as "arc1." We now briefly discuss the formation of the structured features imbedded within this arc. Since the processes which drive the internal structuring of an auroral form are scale dependent it is necessary to first identify the characteristic scales of the structuring observed. For the purposes of the following analysis the largest scale is defined by the width of the arc $\mathrm{w}_{\mathrm{arc}}=25 \mathrm{~km}$. Within this region we identify in Figures 3 
and 8 an elongated S-shaped finer scale feature extending across the field of view and giving the arc a braided 'rope-like' appearance. Normal to the longest dimension of the S-shaped form the width is $\sim 2-4 \mathrm{~km}$. At yet smaller scales $(\sim 2 \times 2 \mathrm{~km})$ there are modulations in the luminosity which appear as wave-like intensity variations on the edges of the arc. These features move in opposite directions on either side of the main symmetry axis of the large scale arc and provide the structuring which makes possible the optical flow analysis. We note that these small features are not readily identifiable from individual snapshots and are best viewed in Movie 1.

[49] The usual mechanism invoked to account for the evolution of auroral arcs in the presence of velocity shear is the Kelvin-Helmholtz instability [Hallinan and Davis, 1970]. This instability is known to occur for plasma flow shears at least twice the transverse Alfvén speed at the altitude where the instability occurs. It was estimated in section 4.1 that $j_{\|}$ is $2.5 \times 10^{-6} \mathrm{~A} / \mathrm{m}^{2}$ averaged over a width of $25 \mathrm{~km}$ at ionospheric altitudes. Application of Ampere's law for a nominal hydrogen plasma density above the acceleration region of $1-10 \mathrm{~cm}^{-3}$ [Strangeway et al., 1998] yields a transverse Alfvén speed of $\sim 300-1000 \mathrm{~km}^{-1}$. From the analysis in section 3 the flow shear across the arc was $\sim 10 \mathrm{~km} / \mathrm{s}$. Since the transverse Alfvén speed and shear velocity both scale with the square root of the geomagnetic field strength, these results show that the threshold for the KelvinHelmholtz instability was not exceeded along the entire flux tube. It is possible however, that this instability may have acted on the smaller scale arc elements embedded within the larger scale optical form. This is particularly true toward the middle of the larger scale current sheet defined by $\mathrm{w}_{\text {arc }}$ where the perturbed magnetic field due to the current was small. It should be noted that the wavelength of the distortion of the elongated fine scale feature mentioned earlier is similar to the $\sim 70 \mathrm{~km}$ field of view of the camera with a transverse width of $\sim 2 \mathrm{~km}$. This provides $\mathrm{k}_{\perp} \mathrm{a} \sim 0.1$ whereas the $\mathrm{K}-\mathrm{H}$ instability is known to grow most strongly for $\mathrm{k}_{\perp} \mathrm{a} \sim 0.6$ (where $\mathrm{a}=1 \mathrm{~km}$ is the half width of the arc element). While it remains possible that the arc structuring was associated with some form of flow shear instability it seems unlikely that the traditionally invoked Kelvin-Helmholtz instability was active in structuring the arc on spatial scales resolvable from Reimei.

[50] It has been suggested by Seyler [1990] that the tearing instability may be more commonly active in the structuring of auroral forms than the Kelvin-Helmholtz instability. For the low beta plasmas above the aurora this instability is active in current sheets with transverse scales similar to and less than the electron inertial length $\lambda_{\mathrm{e}}$. For periodic current sheets with wave number $\mathrm{k}_{\perp}$ the appropriate scale is $\mathrm{k}_{\perp} \lambda_{\mathrm{e}}$, and so for the purposes of this analysis we approximate the unstable scale range as $2 \pi / \mathrm{w}_{\text {arc }} \lambda_{\mathrm{e}} \geq 1$. Using $\mathrm{w}_{\text {arc }}=25 \mathrm{~km}$ we find $2 \pi / \mathrm{w}_{\text {arc }}$ $\lambda_{\mathrm{e}} \geq 1$ for densities $<1 \mathrm{~cm}^{-3}$ consistent with expected densities through the auroral acceleration region. This suggests that the current sheet may have been unstable to the tearing instability. This instability proceeds through reconnection and the formation of magnetic $\mathrm{X}^{-}$and $\mathrm{O}^{-}$points along the symmetry axis of the current sheet. As was shown by Seyler [1990] advection in the sheared flow stretches these features to form S-shaped structures. This form is similar to that observed in the elongated finer scale feature in the center of the main region of luminosity which may have given the arc its 'rope-like' appearance.
[51] Alternatively it is possible that the structuring of the arc was a consequence of an ionospheric mechanism. The localized region of electron precipitation intrinsic to the meso-scale electro-dynamic model discussed in section 4.1 provides conductivity gradients on the scale of the initial current channel or $\mathrm{w}_{\text {arc }}$. For divergence free $\mathrm{J}$ these conductivity gradients cause structuring of $\mathrm{j}_{\|}$and radiate Alfvén waves. The trapping of these waves between the ionosphere and the geomagnetic field-aligned gradients in Alfvén speed above the topside ionosphere (known as the Ionospheric Alfvén Resonator, IAR) or over a whole closed geomagnetic field-line, can drive these gradients unstable. This instability is known as the ionospheric feedback instability [Lysak, 1991] and in the IAR case grows over time scales comparable to the evolution observed. The instability occurs for wave numbers satisfying $\gamma \mathrm{k}_{\perp} \cdot \mathrm{V}_{\mathrm{d}} /\left(\mathrm{V}_{\mathrm{AI}} / \mathrm{h}\right)>2.4$ [Lysak and Song, 2002]. Here $\gamma=1+\mathrm{W}_{\mathrm{ei}} / 35$ [Rees, 1963] is the number of electron-ion pairs produced per incident precipitating electron, $\mathrm{V}_{\mathrm{d}}$ is the relative horizontal drift between ions and electrons (due to $\mathrm{J}_{\mathrm{H}}$ and $\mathrm{J}_{\mathrm{P}}$ ), $\mathrm{V}_{\mathrm{AI}}$ is the Alfvén speed at the ionospheric end of the resonant cavity and $h$ is the ionospheric scale height. As this threshold condition suggests, the growth rate of the instability increases with $\mathrm{k}_{\perp}$. The smallest scale which this instability can produce is limited by the collisional damping for parallel wavelengths approaching $\mathrm{h}$ and less [Lessard and Knudsen, 2001] and Landau damping at scales of the order of the electron inertial length $\left(\lambda_{\mathrm{e}}\right)$. These constraints in the linear case limit the perpendicular scale of the wave driven efficiently through ionospheric feedback to greater than $\sim 1 \mathrm{~km}$. For structuring normal to the main axis of the meso-scale onset arc we take the Pedersen current given by $\mathrm{J}_{\mathrm{H}} / \mathrm{s}=0.075 \mathrm{~A} / \mathrm{m}$ from section 4.1 and a current carrying region of $50 \mathrm{~km}$ in vertical extent [Lysak, 1991] to find $\mathrm{V}_{\mathrm{d}}=$ $100 \mathrm{~m} / \mathrm{s}$. Using the average precipitating energy of $\mathrm{W}_{\mathrm{ei}}=$ $10 \mathrm{keV}$ identified previously, and taking $\mathrm{V}_{\mathrm{AI}}=10^{6} \mathrm{~m} / \mathrm{s}$ with an ionospheric scale height of $200 \mathrm{~km}$ we find that instability to ionospheric feedback occurs for $\mathrm{k}_{\perp}>3.0 \times 10^{-4} \mathrm{~m}^{-1}$. This will lead to periodic structuring on widths normal to the main axis of the arc on scales less than $\sim 20 \mathrm{~km}$. Smaller values of the Pedersen current will provide a proportionally smaller unstable scale range. Alternatively, gradients in the Hall current using the same parameters will provide periodic structuring along the arc on scales less than $\sim 60 \mathrm{~km}$. This process will lead to striations along the main axis of the arc which eventually break the arc into a number of narrow more intense elongated features. As in the case of the tearing instability, the advection of $j_{\|}$in the sheared flow through the acceleration region will act to distort the striations in a manner which may provide elongated S-shaped features and the 'rope-like' appearance of the arc shown in Figure 8. While this may provide a plausible account, a caveat in this interpretation is that the structuring in the IAR must extend into the acceleration region where the flow shear drives the distortion. This is dependent on the details of the altitude dependent Alfvén speed profile [Streltsov and Lotko, 2004] which cannot be estimated from the observations available for this event.

[52] Finally, for the smallest features observed $(\sim 2 \times 2 \mathrm{~km})$ instabilities associated with transverse $\mathrm{j}_{\|}$gradients and smallscale flow shears through the acceleration region are possible formative processes [Seyler, 1990; Seyler and Wu, 2001; Wu and Seyler, 2003; Asamura et al., 2009]. These features are 
however not so well resolved by the Reimei camera. Because of this, and for the sake of brevity, we reserve a consideration of the processes leading to the structuring on these scales to a future study.

\section{Conclusions}

[53] We presented observations and a detailed analysis of a substorm onset auroral arc. The large-scale observation by all-sky cameras monitored the dynamic evolution of the onset arc through the generation of a new arc poleward of the pre-existing growth-phase arc. Though the substorm onset is not a prime topic of this report it is interesting to note that previous reports mentioned the generation of a new arc equatorward of the pre-existing arc a few minutes prior to onset [Lyons et al., 2002]. At this moment it is not clear if the current case represents an exception from the general rule or if only the superior temporal resolution of the THEMIS all-sky imagers adds this new view.

[54] Reimei provided high spatial and temporal observations of the aurora for just a few seconds around the onset time but combined with the all-sky observations and a full model of the auroral excitation it was possible to extract the energy flux and peak energy of the precipitating electrons. Together with the optical information about arc width and the speed of structures it allowed for a detailed comparison between observed and theoretically predicted properties of the poleward arc during substorms [Haerendel, 2009]. Both arcs could be identified as inverted-V type arcs with an additional Alfvén wave acceleration component at the poleward edge of the onset arc. The Alfvén wave accelerated electrons did not contribute much to the auroral arc brightness but contributed to the field-aligned current and the width of the current structure.

[55] The lack of magnetic field measurements from the low altitude spacecraft made it difficult to determine the distribution of field-aligned currents. The spatial resolution of the reconstructed current systems was not sufficient $(300 \mathrm{~km})$ for such a detailed reconstruction. We can speculate that the downward current that connects to the upward current of the newly developed onset arc was located poleward of it. Such a current distribution would fit the view of the development of the feedback instability in the downward current region [Streltsov and Lotko, 2003, 2004] together with Alfvén wave resonances and the formation of small-scale disturbances at the interface between the downward and upward currents as seen in the particle and optical data at the poleward edge of the large-scale inverted-V arc. The advection of current structuring generated through the ionospheric feedback instability could contribute to the fast motion of small-scale structures on the poleward boundary of the arc. Alternatively the structuring observed may have been a consequence of the action of current sheet instabilities through the acceleration region [Seyler, 1990; Seyler and Wu, 2001; Wu and Seyler, 2003] where it seems likely that the action of the tearing instability was responsible for the rope-like appearance observed.

[56] The magnetospheric observations by two THEMIS spacecraft provided a view of the magnetospheric structure around the time of the substorm onset. Both spacecraft encountered the eastern edge of a bursty bulk flow in the magnetosphere. The reconstruction of the current distribution for the first encounter was consistent with a corresponding upward field-aligned current further to the west, where the main auroral activity happened. The analysis of the flow disturbance suggested an eastward motion of the FAC pattern, consistent with the eastward expansion of the azimuthally aligned arc. Overall the THEMIS observations confirmed the auroral observations with the eastward expansion of the substorm onset aurora. More importantly they provide the density and temperatures of the source region plasma in the magnetosphere allowing for the quantitative analysis of the observations.

[57] Acknowledgments. The authors acknowledge the support of the International Space Science Institute (ISSI) for the organization of a team on small-scale auroral structures and the opportunity to discuss and exchange ideas in its facilities in Bern, Switzerland. We acknowledge NASA contract NAS5-02099 and V. Angelopoulos for use of data from the THEMIS Mission. Specifically: S. Mende and E. Donovan for use of the ASI data, and the CSA for logistical support in fielding and data retrieval from the GBO stations, C. W. Carlson and J. P. McFadden for use of ESA data, K. H. Glassmeier, U. Auster and W. Baumjohann for the use of FGM data provided under the lead of the Technical University of Braunschweig and with financial support through the German Ministry for Economy and Technology and the German Aerospace Center (DLR) under contract 50 OC 0302. We would like to thank Y. Ebihara for the development of the optical flow analysis software. We acknowledge A. Yamazaki, Y. Kasaba, and other members of the Reimei (INDEX) mission for the use of Reimei data. C. C. was in part supported by NSF grant ATM-0602728.

[58] Robert Lysak thanks Octav Marghitu and Larry Lyons for their assistance in evaluating this paper.

\section{References}

Amm, O. (1997), Ionospheric elementary current systems in spherical coordinates and their application, J. Geomag. Geoelectr., 49, 947-955.

Amm, O., and A. Viljanen (1999), Ionospheric disturbance magnetic field continuation from the ground to ionosphere using spherical elementary current systems, Earth Planets Space, 51, 431-440.

Amm, O., M. J. Engebretson, T. Hughes, L. Newitt, A. Viljanen, and J. Watermann (2002), A traveling convection vortex event study: Instantaneous equivalent currents, estimation of field-aligned currents, and the role of induced currents, J. Geophys. Res., 107(A11), 1334, doi:10.1029/2002JA009472.

Amm, O., et al. (2005), Coordinated studies of the Geospace environment using Cluster, satellite and ground-based data: An interim review, Ann. Geophys., 23, 2129-2170, doi:10.5194/angeo-23-2129-2005.

Angelopoulos, V. (2008), The THEMIS Mission, Space Sci. Rev., 141, 5-34, doi:10.1007/s11214-008-9336-1.

Asamura, K., D. Tsujita, H. Tanaka, Y. Saito, T. Mukai, and M. Hirahara (2003), Auroral particle instrument onboard the INDEX satellite, Adv. Space Res., 32, 375-378, doi:10.1016/S0273-1177(03)90275-4.

Asamura, K., et al. (2009), Sheared flows and small-scale Alfvén wave generation in the auroral acceleration region, Geophys. Res. Lett., 36 , L05105, doi:10.1029/2008GL036803.

Baumjohann, W., R. J. Pellinen, H. J. Opgenoorth, and E. Nielsen (1981) Joint two-dimensional observations of ground magnetic and ionospheric electric fields associated with auroral zone currents: Current systems associated with local auroral break-ups, Planet. Space Sci., 29, 431447, doi:10.1016/0032-0633(81)90087-8

Boström, R. (1964), A model of the auroral electrojects, J. Geophys. Res., 69, 4983-4999, doi:10.1029/JZ069i023p04983.

Boudouridis, A., and H. Spence (2007), Separation of spatial and temporal structure of auroral particle precipitation, J. Geophys. Res., 112, A12217, doi:10.1029/2007JA012591.

Bryant, D. A. (2002), The roles of static and dynamic electric fields in the auroral acceleration region, J. Geophys. Res., 107(A6), 1077, doi:10.1029/2001JA900162.

Chaston, C. C., C. W. Carlson, W. J. Peria, R. E. Ergun, and J. P. McFadden (1999), FAST observations of inertial Alfvén waves in the dayside aurora, Geophys. Res. Lett., 26, 647-650, doi:10.1029/ 1998GL900246.

Chaston, C. C., C. W. Carlson, J. P. McFadden, R. E. Ergun, and R. J. Strangeway (2007), How important are dispersive Alfvén waves for auroral particle acceleration?, Geophys. Res. Lett., 34, L07101, doi:10.1029/ 2006GL029144. 
Davis, T. N. (1978), Observed characteristics of auroral forms, Space Sci. Rev., 22, 77-113, doi:10.1007/BF00215814.

Davis, T. N., and T. J. Hallinan (1976), Auroral spirals. 1. Observations, J. Geophys. Res., 81, 3953-3958, doi:10.1029/JA081i022p03953.

Elphinstone, R. D., J. S. Murphree, and L. L. Cogger (1996), What is a global auroral substorm?, Rev. Geophys., 34, 169-232, doi:10.1029/ 96RG00483.

Frey, H. U. (2007), Localized aurora beyond the auroral oval, Rev. Geophys., 45, RG1003, doi:10.1029/2005RG000174.

Frey, H. U., G. Haerendel, D. Knudsen, S. Buchert, and O. H. Bauer (1996), Optical and radar observations of the motion of auroral arcs, J. Atmos. Terr. Phys., 58, 57-69, doi:10.1016/0021-9169(95)00019-4.

Fridman, M., and J. Lemaire (1980), Relationship between auroral electrons fluxes and field aligned electric potential difference, J. Geophys. Res., 85, 664-670, doi:10.1029/JA085iA02p00664.

Fukushima, N. (1976), Generalized theorem for no ground magnetic effect of vertical currents connected with Pedersen currents in the uniformconductivity ionosphere, Rep. Ionos. Space Res. Jpn., 30, 35-40.

Haerendel, G. (1999), Origin and dynamics of thin auroral arcs, Adv. Space Res., 23, 1637, doi:10.1016/S0273-1177(99)00374-9.

Haerendel, G. (2007), Auroral arcs as sites of magnetic stress release, J. Geophys. Res., 112, A09214, doi:10.1029/2007JA012378.

Haerendel, G. (2009), Poleward arcs of the auroral oval during substorms and the inner edge of the plasma sheet, J. Geophys. Res., 114 A06214, doi:10.1029/2009JA014138.

Haerendel, G., B. U. Olipitz, S. Buchert, O. H. Bauer, E. Rieger, and C. La Hoz (1996), Optical and radar observations of auroral arcs with emphasis on small-scale structures, J. Atmos. Terr. Phys., 58, 71-83, doi:10.1016/0021-9169(95)00020-8.

Hallinan, T. J. (1976), Auroral spirals. 2. Theory, J. Geophys. Res., 81, 3959-3965, doi:10.1029/JA081i022p03959.

Hallinan, T. J. (1981), The distribution of vorticity in auroral arcs, in Physics of Auroral Arc Formation, Geophys. Monogr. Ser., vol. 25, edited by S.-I. Akasofu and J. R. Kan, pp. 42-49, AGU, Washington, D. C.

Hallinan, T. J., and T. N. Davis (1970), Small-scale auroral arc distortions, Planet. Space Sci., 18, 1735, doi:10.1016/0032-0633(70)90007-3.

Hedin, A. E. (1991), Extension of the MSIS thermospheric model into the middle and lower atmosphere, J. Geophys. Res., 96, 1159-1172, doi:10.1029/90JA02125

Henderson, M. G., G. D. Reeves, and J. S. Murphree (1998), Are northsouth aligned auroral structures an ionospheric manifestation of bursty bulk flows?, Geophys. Res. Lett., 25, 3737, doi:10.1029/98GL02692.

Horn, B. K. P., and B. G. Schunck (1981), Determining optical flow, Artif. Intell., 17, 185, doi:10.1016/0004-3702(81)90024-2.

Knight, S. (1973), Parallel electric fields, Planet. Space Sci., 21, 741-750, doi:10.1016/0032-0633(73)90093-7.

Lanchester, B. S., M. H. Rees, D. Lummerzheim, A. Otto, H. U. Frey, and K. U. Kaila (1997), Large fluxes of auroral electrons in filaments of $100 \mathrm{~m}$ width, J. Geophys. Res., 102, 9741-9748, doi:10.1029/97JA00231.

Lanchester, B. S., et al. (1998), Ionospheric response to variable electric fields in small scale auroral structures, Ann. Geophys., 16(10), 1343-1354 doi:10.1007/s00585-998-1343-8.

Lanchester, B. S., et al. (2001), Ohmic heating as evidence for strong fieldaligned currents in filamentary aurora, J. Geophys. Res., 106, 1785-1794 doi:10.1029/1999JA000292.

Laundal, K. M., and N. Østgaard (2009), Asymmetric auroral intensities in the Earth's Northern and Southern Hemispheres, Nature, 460, 491-493, doi:10.1038/nature08154

Lessard, M. R., and D. J. Knudsen (2001), Ionospheric reflection of smallscale Alfvén waves, Geophys. Res. Lett., 28, 3573, doi:10.1029/ 2000GL012529.

Lummerzheim, D., and J. Lilensten (1994), Electron transport and energy degradation in the ionosphere: Evaluation of the numerical solution comparison with laboratory experiments and auroral observations, Ann. Geophys., 12, 1039-1051.

Lyons, L. R., I. O. Voronkov, E. F. Donovan, and E. Zesta (2002), Relation of substorm breakup arc to other growth-phase auroral arcs, J. Geophys. Res., 107(A11), 1390, doi:10.1029/2002JA009317.

Lysak, R. L. (1991), Feedback instability of the ionospheric resonant cavity, J. Geophys. Res., 96, 1553-1568, doi:10.1029/90JA02154.

Lysak, R. L., and Y. Song (2002), Energetics of the ionospheric feedback instability, J. Geophys. Res., 107(A8), 1160, doi:10.1029/2001JA000308.

Maggs, J., and T. Davis (1968), Measurements of the thickness of aurora structures, Planet. Space Sci., 16, 205, doi:10.1016/0032-0633(68) 90069-X.

Marghitu, O., B. Klecker, G. Haerendel, and J. McFadden (2004), ALADYN: Method to investigate auroral arc electrodynamics from satellite data, J. Geophys. Res., 109, A11305, doi:10.1029/2004JA010474.
Marghitu, O., T. Karlsson, B. Klecker, G. Haerendel, and J. McFadden (2009), Auroral arc and oval electrodynamics in the Harang region, J. Geophys. Res., 114, A03214, doi:10.1029/2008JA013630.

Mende, S. B., C. W. Carlson, H. U. Frey, L. M. Peticolas, and N. Ostgaard (2003a), FAST and IMAGE-FUV observations of a substorm onset, J. Geophys. Res., 108(A9) 1344, doi:10.1029/2002JA009787.

Mende, S. B., C. W. Carlson, H. U. Frey, T. J. Immel, and J-C Gerard (2003b), IMAGE-FUV and in situ FAST particle observations of substorm aurorae, J. Geophys. Res., 108(A4), 8010, doi:10.1029/ 2002JA009413.

Mende, S. B., S. E. Harris, H. U. Frey, V. Angelopoulos, C. T. Russell, E. Donovan, B. Jackel, M. Greffen, and L. M. Peticolas (2008), The THEMIS array of ground-based observatories for the study of auroral substorms, Space Sci. Rev., 141, 357-387, doi:10.1007/s11214-008-9380-x. Obuchi, Y., T. Sakanoi, A. Yamazaki, T. Ino, S. Okano, Y. Kasaba, M. Hirahara, Y. Kanai, and N. Takeyama (2008), Initial observations of auroras by the multi-spectral auroral camera on board the Reimei satellite, Earth Planets Space, 60, 827-835.

Oguti, T. (1974), Rotational deformations and related drift motions of auroral arcs, J. Geophys. Res., 79, 3861-3865, doi:10.1029/JA079i025p03861.

Persoon, A. M., D. A. Gurnett, W. K. Peterson, J. H. Waite, J. L. Burch, and J. L. Green (1988), Electron density depletions in the nightside auroral zone, J. Geophys. Res., 93, 1871-1895, doi:10.1029/JA093iA03p01871.

Rees, M. H. (1963), Auroral ionization and excitation by incident energetic electrons, Planet. Space Sci., 11, 1209, doi:10.1016/0032-0633(63)90252-6.

Rees, M. H., and D. Luckey (1974), Auroral electron energy derived from ratio of spectroscopic emissions I. Model computations, J. Geophys. Res., 79, 5181-5186, doi:10.1029/JA079i034p05181.

Robinson, R. M., R. R. Vondrak, K. Miller, T. Dabbs, and D. Hardy (1987), On calculating ionospheric conductances from the flux and energy of precipitating electrons, J. Geophys. Res., 92, 2565-2569, doi:10.1029/JA092iA03p02565.

Saito, H., et al. (2005), An overview and initial in-orbit status of "INDEX" satellite, IEIC Tech. Rep., 105, 29-34

Sakanoi, T., S. Okano, Y. Obuchi, T. Kobayashi, M. Ejiri, K. Asamura, and M. Hirahara (2003), Development of the multi-spectral auroral camera onboard the INDEX satellite, Adv. Space Res., 32, 379-384, doi:10.1016/S0273-1177(03)90276-6.

Séran, E., H. U. Frey, M. Fillingim, J.-J. Berthelier, R. Pottelette, and G. Parks (2007), Demeter high resolution observations of the ionospheric thermal plasma response to magnetospheric energy input during the magnetic storm of November 2004, Ann. Geophys., 25, 2503-2511, doi:10.5194/angeo-25-2503-2007.

Séran, E., M. Godefroy, K. Kauristie, J.-C. Cerisier, J.-J. Berthelier, M. Lester, and L.-E. Sarri (2009), What can we learn from HF signal scattered from a discrete arc? Ann. Geophys., 27, 1887-1896, doi:10.5194/angeo-27-18872009.

Seyler, C. E. (1990), A mathematical model of the structure and evolution of small-scale discrete auroral arcs, J. Geophys. Res., 95, 17,199-17,215, doi:10.1029/JA095iA10p17199.

Seyler, C. E., and K. Wu (2001), Instability at the electron inertial scale, J. Geophys. Res., 106, 21,623-21,644, doi:10.1029/2000JA000410.

Steele, D. P., and D. J. McEwen (1990), Electron auroral excitation efficient and intensity ratios, J. Geophys. Res., 95, 10,321-10,336 doi:10.1029/JA095iA07p10321.

Strangeway, R. J., et al. (1998), FAST observations of VLF waves in the auroral zone: Evidence of very low plasma densities, Geophys. Res. Lett., 25, 2065-2068, doi:10.1029/98GL00664.

Strangeway, R. J., et al. (2005), Factors controlling ionospheric outflows at intermediate altitudes, J. Geophys. Res., 110, A03221, doi:10.1029/ 2004JA010829.

Streltsov, A. V., and W. Lotko (2003), Small-scale electric fields in downward auroral currents, J. Geophys. Res., 108(A7), 1289, doi:10.1029/ 2002JA009806

Streltsov, A. V., and W. Lotko (2004), Multiscale electrodynamics of the ionosphere-magnetosphere system, J. Geophys. Res., 109, A09214, doi:10.1029/2004JA010457.

Trondsen, T. S., and L. L. Cogger (2001), Fine-scale optical observations of aurora, Phys Chem Earth., 26, 179-188.

Vogt, J., H. U. Frey, G. Haerendel, H. Hoefner, and J. L. Semeter (1999), Shear velocity profiles associated with auroral curls, J. Geophys. Res., 104, 17,277, doi:10.1029/1999JA900148.

Wagner, J., R. Sydora, T. Tajima, T. Hallinan, L. Lee, and S. I. Akasofu (1983), Small-scale auroral arc deformations, J. Geophys. Res., 88, 8013, doi:10.1029/JA088iA10p08013.

Wu, K., and C. E. Seyler (2003), Instability of inertial Alfvén waves in transverse sheared flow, J. Geophys. Res., 108(A6), 1236 , doi:10.1029/2002JA009631. 
Wuttke, S., G. Seckmeyer, and G. Koenig-Langlo (2006), Measurements of spectral snow albedo at Neumayer, Antarctica, Ann. Geophys., 24, 7-21, doi:10.5194/angeo-24-7-2006

O. Amm and L. Juusola, Finnish Meteorological Institute, Arctic Research Unit, P.O. Box 503, FIN-00101 Helsinki, Finland.

K. Asamura, Institute of Space and Astronautical Science, Japan Aerospace Exploration Agency, Kanagawa 229-8510, Japan.

C. C. Chaston and H. U. Frey, Space Sciences Laboratory, University of California, Berkeley, CA 94720, USA. (hfrey@ssl.berkeley.edu)

S. Fu, School of Earth and Space Sciences, Peking University, Beijing, 100871, China.

G. Haerendel, Max-Planck-Institut fuer Extraterrestrische Physik, Giessenbachstr., D-85748 Garching, Germany.

M. Hirahara, Department of Earth and Planetary Science, Graduate School of Science, University of Tokyo, Tokyo 113-0033, Japan.
T. Karlsson, Space and Plasma Physics, School of Electrical Engineering, KTH, S-10044 Stockholm, Sweden.

B. Lanchester and D. Whiter, School of Physics and Astronomy, University of Southampton, Southampton, SO17 1BJ, U.K.

R. Nakamura, Space Research Institute, Austrian Academy of Sciences, Schmiedlstr. 6, A-8042 Graz, Austria.

N. Østgaard, Department of Physics and Technology, University of Bergen, Allegt. 55, Bergen N-5007, Norway.

T. Sakanoi, Planetary Plasma and Atmospheric Research Center, Graduate School of Science, Tohoku University, Aramaki-aza-aoba, Aoba, Sendai 980-8578, Japan.

E. Séran, LATMOS, IPSL, 4 avenue de Neptune, St-Maur des Fosses, F-94100, France.

J. Weygand, IGPP, University of California, Los Angeles, CA 90095 , USA. 